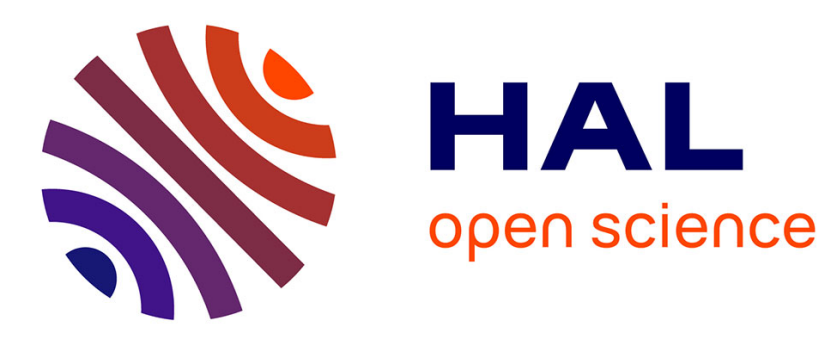

\title{
Cobalt-Catalyzed Cross-Couplings between Alkyl Halides and Grignard Reagents
}

\author{
Amandine Guérinot, Janine Cossy
}

\section{To cite this version:}

Amandine Guérinot, Janine Cossy. Cobalt-Catalyzed Cross-Couplings between Alkyl Halides and Grignard Reagents. Accounts of Chemical Research, 2020, 53 (7), pp.1351-1363. 10.1021/acs.accounts.0c00238 . hal-03197963

\section{HAL Id: hal-03197963 https://hal.science/hal-03197963}

Submitted on 8 Jun 2021

HAL is a multi-disciplinary open access archive for the deposit and dissemination of scientific research documents, whether they are published or not. The documents may come from teaching and research institutions in France or abroad, or from public or private research centers.
L'archive ouverte pluridisciplinaire HAL, est destinée au dépôt et à la diffusion de documents scientifiques de niveau recherche, publiés ou non, émanant des établissements d'enseignement et de recherche français ou étrangers, des laboratoires publics ou privés. 


\section{Cobalt-catalyzed cross-couplings between alkyl halides and Grignard reagents \\ AMANDINE GUERINOT, JANINE COSSY. \\ Molecular, Macromolecular Chemistry and Materials, ESPCI Paris, CNRS, PSL University, 10 rue Vauquelin, 75005 Paris, France.}

RECEIVED ON DATE GOES HERE.

\section{O NS P E C T US}

Metal-catalyzed cross-couplings have emerged as essential tools for the construction of C-C bonds. The identification of efficient catalytic systems as well as large substrate scope made these cross-couplings key reactions to access valuable molecules ranging from materials, agrochemicals to active pharmaceutical ingredients. They have been increasingly integrated in retrosynthetic plans allowing shorter and original route development. Palladium-catalyzed cross-couplings still largely rule the field, the most popular reactions in industrial processes being the Suzuki and Sonogashira couplings. However, the extensive use of palladium complexes raises several problems such as limited resources, high cost, environmental impact and frequent need for sophisticated ligands. As a consequence, the use of non-precious and cheap metal catalysts has appeared as a new horizon in cross-coupling development. Over the three last decades, a growing interest has thus been devoted to $\mathrm{Fe}-$, $\mathrm{Co}-\mathrm{Cu}-$ or Ni-catalyzed cross-couplings. Their natural abundance makes them cost-effective allowing the conception of more sustainable and less expensive chemical processes, especially for large-scale production of active molecules. Besides these economical and environmental considerations, the $3 \mathrm{~d}$ metal catalysts also exhibit complementary reactivity with palladium complexes, facilitating the use of alkyl halide partners due to the decrease of $\beta$-elimination side-reactions. In particular, by using cobalt catalysts numerous cross-couplings between alkyl halides and organometallics have been described. However, cobalt catalysis still stays far behind palladium catalysis in terms of popularity and applications and the expansion of the substrate scope as well as the development of simple and robust catalytic systems remains an important challenge.

In 2011, our group entered the cobalt catalysis field by developing a cobalt-catalyzed cross-coupling between $C$-bromo glycosides and Grignard reagents. The generality of the coupling allowed the preparation of a range of valuable $C$-aryl and $C$-vinyl glycosides building blocks. We then focused on the functionalization of saturated $N$-heterocycles and a variety of halo-azetidines, -pyrrolidines and -piperidines were successfully reacted with aryl and alkenyl Grignard reagents under cobalt catalysis. With the objective of preparing valuable $\alpha$-aryl amides, a cobalt-catalyzed cross-coupling applied to $\alpha$-bromo amides was studied and then extended to $\alpha$-bromo lactams. Recently, we also reported an efficient and general cross-coupling involving cyclopropyl- and cyclobutyl- magnesium bromides. This method allows the alkylation of functionalized small strained rings by a range of primary and secondary alkyl halides.

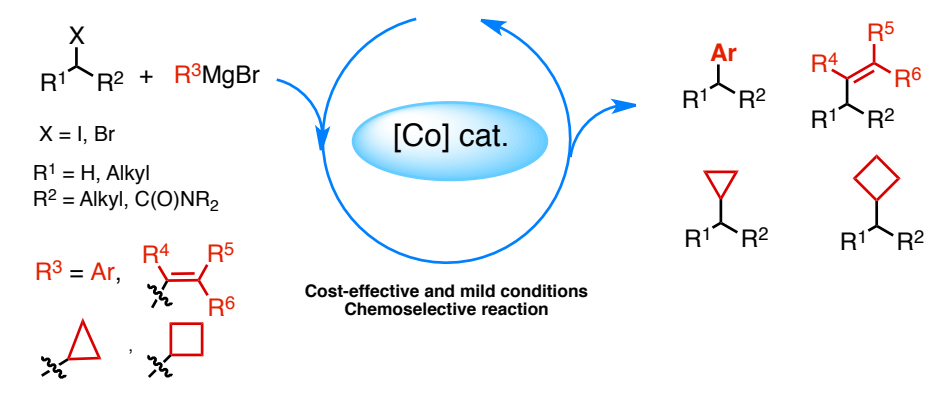




\section{1- Introduction}

Transition metal-catalyzed cross-couplings have emerged as essential tools for organic chemists working in various fields ranging from pharmaceutical and agrochemical industries to material science. ${ }^{1}$ Particularly, palladium-catalyzed Suzuki cross-coupling has entered among the top five reactions carried out by medicinal chemists in drug discovery, development and production. ${ }^{2}$ However, the extensive use of palladium catalysis now starts to raise some questions related to the high cost of the complexes and/or ligands, the difficulty of extraction of the palladium, the depletion of the resource and the toxicity of the metal traces applying purification issues. ${ }^{3}$ All these economical, environmental and toxicity considerations can explain the increasing interest that has been devoted to sustainable metal-catalyzed cross-couplings over the last three decades. ${ }^{4}$ Sustainability includes cost-efficiency, earth abundance and low environmental impact. Iron, ${ }^{5}$ copper, ${ }^{6}$ cobalt $^{7}$ and nickel ${ }^{8}$ catalysts fit these requirements, in part, and have been shown to efficiently promote cross-couplings between halides and organometallics. ${ }^{9}$ Besides the advantages listed below, these catalysts also exhibit original chemical reactivity that can be complementary to palladium complexes. They notably allow the use of alkyl halide partners that are known to be reluctant to palladium-catalyzed cross-couplings due to the undesirable $\beta$ elimination. ${ }^{10}$ In addition, they are compatible with the use of non-expensive and robust organometallics such as Grignard reagents and organozinc derivatives. Particularly, cobalt catalysis appears quite general for the arylation, alkenylation and even alkylation of alkyl (pseudo)halides. ${ }^{7}$ The pioneering work on cobalt-catalyzed alkyl halide arylation using Grignard reagents were reported in 2001 by Oshima et al. ${ }^{11}$ Bromo acetals, featuring an insaturation, such as 1.1 were shown to undergo a tandem radical cyclization/cross-coupling when treated with phenylmagnesium bromide in the presence of a cobalt biphosphine complex (Scheme 1). The 
corresponding tetrahydrofuran was obtained with a good yield of $80 \%$ and a perfect control of the relative stereochemistry of the two adjacent stereocenters created during the reaction.

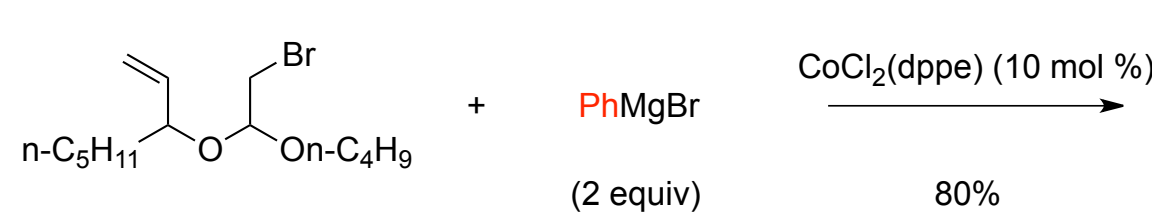

1.1

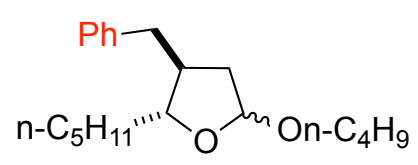

$1.2(d r=55: 45)$

dppe $=1,2$-bis (diphenylphosphino)ethane

Scheme 1. Cobalt-catalyzed sequential cyclization/arylation of a bromo acetal with $\mathrm{PhMgBr}$.

Thereafter, several catalytic systems including a cobalt complex were developed to perform the cross-coupling between a range of alkyl halides and (hetero)aryl Grignard reagents. The use of 1,3-bis(diphenylphosphino)propane (dppp) associated with $\mathrm{CoCl}_{2}$ allowed the (hetero)arylation of various primary iodides and bromides with moderate yields (Table 1 , entry 1 ). ${ }^{12}$ Changing the bisphosphine for a diamine, such as TetraMethylCyclohexaneDiamine (TMCD), made significant improvements both in terms of yields in cross-coupling products and scope extension (Table 1 , entry 2). ${ }^{13}$ The reaction could be carried out on primary as well as secondary halides and was compatible with functional groups such as acetals or esters. The chemoselectivity of cobalt-catalyzed cross-coupling was further highlighted by Cahiez et al. who developed a robust catalytic system $\left[\mathrm{Co}(\mathrm{acac})_{3}, N, N, N^{\prime} N^{\prime}\right.$-tetramethylethylenediamine (TMEDA)] for the arylation of primary and secondary alkyl bromides (Table 1, entry 3). ${ }^{14}$ Electrophilic moieties such as esters, amides or alkyl chlorides were tolerated under these conditions. More recently, Knochel et al. focused on the cobalt-catalyzed arylation of polysubstituted cycloalkyl iodides (Table 1, entries 4-5). ${ }^{15}$ The use of $\mathrm{CoCl}_{2} \cdot 2 \mathrm{LiCl}$ together with either TMEDA or neocuproine resulted in the highly diastereoselective arylation of a range of cycloalkyl iodides/bromides including iodo- 
tetrahydropyrans and iodo-pyrrolidines. Interestingly, some heteroaryl Grignard reagents, incorporating an indole or a pyrimidine, were used successfully. ${ }^{16}$

\begin{tabular}{|c|c|c|c|c|}
\hline$(x=1$, & (Het)Ar & [Co] cat, L & & $\begin{array}{l}\text { tet) } \mathrm{Ar} \\
\mathrm{R}^{2}\end{array}$ \\
\hline entry & substrates & catalytic system & yield & ref. \\
\hline 1 & $\begin{array}{l}\text { Mostly } \\
\text { primary } \\
\text { halides (I, Br) }\end{array}$ & $\begin{array}{l}\mathrm{CoCl}_{2}(10 \mathrm{~mol} \%) \\
\operatorname{dppp}(12 \mathrm{~mol} \%)\end{array}$ & $24-67 \%$ & 12 \\
\hline 2 & $\begin{array}{l}\text { Primary and } \\
\text { secondary } \\
\text { halides (I, Br) }\end{array}$ & $\begin{array}{l}\mathrm{CoCl}_{2}(5 \mathrm{~mol} \%) \\
\operatorname{TMCD}(6 \mathrm{~mol} \%)\end{array}$ & $56-99 \%$ & 13 \\
\hline 3 & $\begin{array}{l}\text { Primary and } \\
\text { secondary } \\
\text { bromides }\end{array}$ & $\begin{array}{l}\operatorname{Co}(\operatorname{acac})_{3}(5 \mathrm{~mol} \%) \\
\operatorname{TMEDA}(5 \mathrm{~mol} \%)\end{array}$ & $16-98 \%$ & 14 \\
\hline 4 & $\begin{array}{l}\text { Cycloalkyl } \\
\text { iodides }\end{array}$ & $\begin{array}{l}\mathrm{CoCl}_{2} \cdot 2 \mathrm{LiCl}(85 \mathrm{~mol} \%) \\
\text { TMEDA }(30 \mathrm{~mol} \%)\end{array}$ & $55-91 \%$ & $15 \mathrm{a}$ \\
\hline 5 & $\begin{array}{l}\text { Cycloalkyl } \\
\text { iodides }\end{array}$ & $\begin{array}{l}\mathrm{CoCl}_{2} \cdot 2 \mathrm{LiCl}(50 \mathrm{~mol} \%) \\
\text { neocuproine }(20 \mathrm{~mol} \%)\end{array}$ & $54-88 \%$ & $15 b$ \\
\hline
\end{tabular}

Table 1. Various cobalt catalytic systems for the arylation of alkyl halides with Grignard reagents.

Compared to the arylations, only a few examples of cobalt-catalyzed alkenylations of alkyl halides are reported in the literature. Besides one isolated example reported by Oshima et al. (Scheme 2, eq. 1), ${ }^{13 a}$ cross-couplings involving 1-(trimethylsilyl)ethenylmagnesium bromide were studied. ${ }^{17}$ Using $\mathrm{Co}(\mathrm{acac})_{3}$ in TMEDA allowed the successful vinylation of a range of primary and secondary alkyl halides (Scheme 2, eq. 2). 


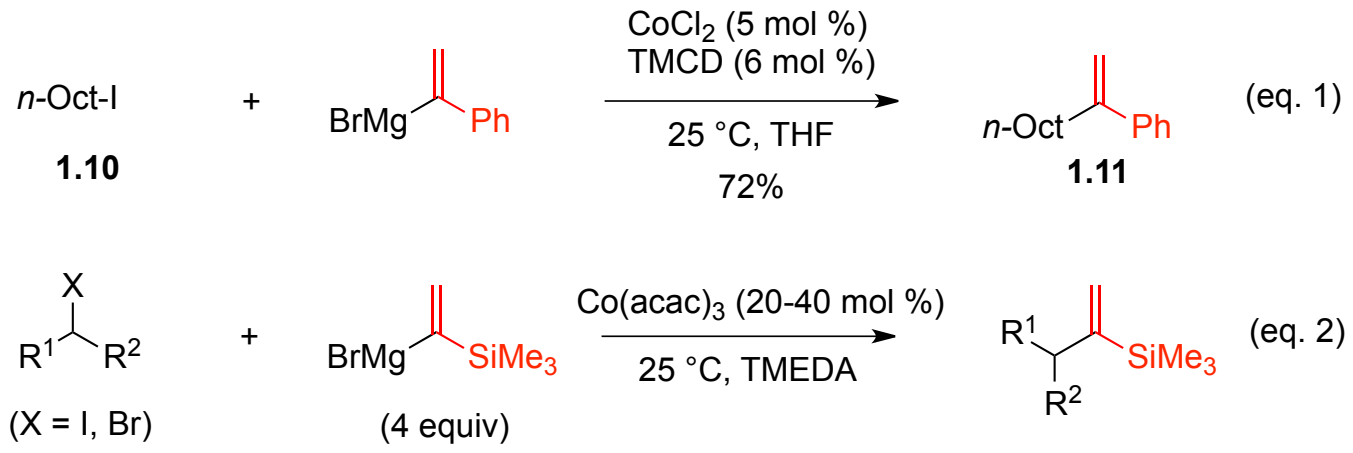

Scheme 2. Cobalt-catalyzed alkenylation of alkyl halides with Grignard reagents.

Cobalt-catalyzed alkyl-alkyl coupling still remains an important challenge and examples of alkylation of non-activated halides (i.e. non allylic or benzylic halides) are quite rare. After their early reports on the allylation and benzylation of alkyl halides,$^{18}$ Oshima et al. described a sequential cyclization/cross-coupling between alkyl halides and allyldimethylsilylmethylmagnesium chloride. ${ }^{19}$ The combination of $\mathrm{CoCl}_{2}$ with a $\mathrm{N}$-heterocyclic carbene (NHC) ligand allowed the formation of the cyclic compounds with good yields (Scheme 3).

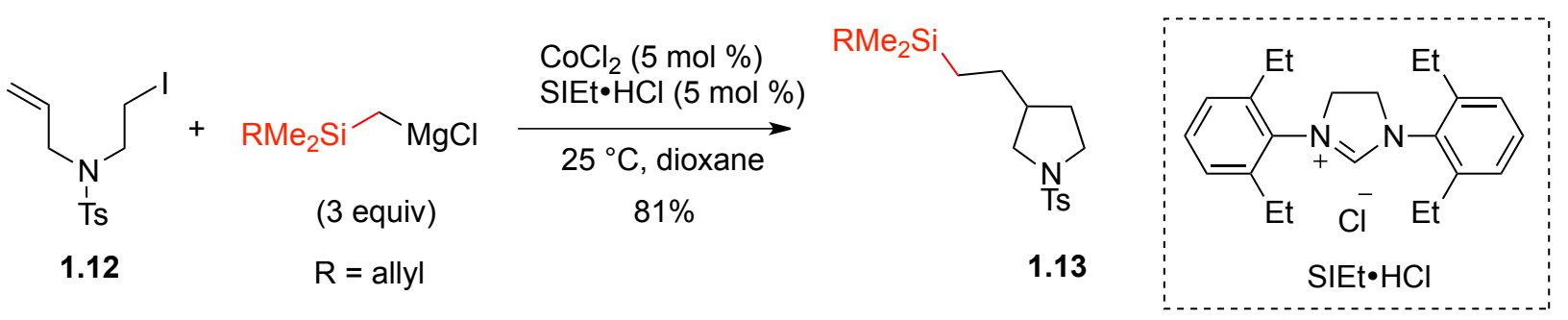

Scheme 3. Cobalt-catalyzed tandem cyclization/cross-coupling between alkyl halides and an alkyl Grignard reagent. 
To date, one of the most general methods for alkyl-alkyl coupling was developed by Cahiez et al. who employed $\mathrm{CoCl}_{2} \cdot 2 \mathrm{LiI}$ associated with TMEDA to perform the alkylation of primary and secondary functionalized alkyl bromides (Scheme 4$){ }^{20}$

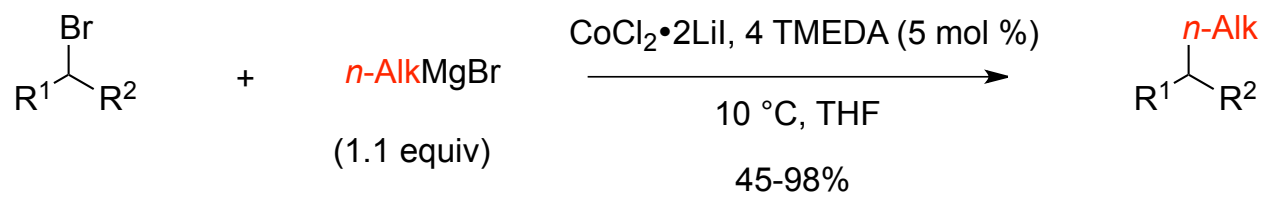

Scheme 4. Cobalt-catalyzed cross-coupling between alkyl bromides and alkyl Grignard reagents.

In 2013, the addition of isoprene, as the ligand, to a mixture of $\mathrm{CoCl}_{2}$ and $\mathrm{LiI}$ was shown to be beneficial for the coupling of tertiary alkyl Grignard reagents with primary alkyl bromides (Scheme 5, eq. 1). ${ }^{21}$ Again, the reaction proved to be highly chemoselective towards several sensitive functional groups such as esters, amides and even secondary alkyl bromides. The reaction was further extended to the alkylation of alkyl fluorides by using 1,3-pentadiene instead of isoprene (Scheme 5, eq. 2). ${ }^{22,23}$ 


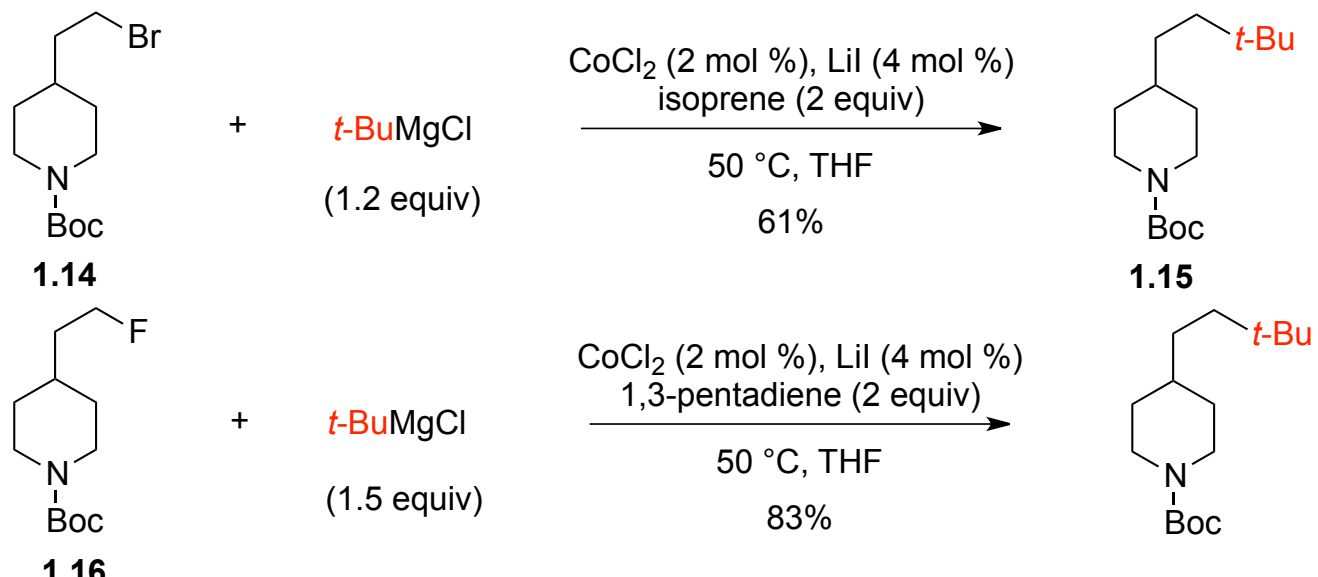

(eq. 1)

1.16

Scheme 5. Cobalt-catalyzed cross-coupling of alkyl bromides and fluorides with tertiary alkyl Grignard reagents.

Despite all these promising reports, cobalt-catalyzed cross-couplings remain far behind palladium-catalyzed cross-couplings in term of popularity, especially in the industrial community. To overcome this under-utilization, the robustness as well as the broad substrate scope of cobalt-catalyzed cross-couplings still needs to be highlighted through original reports. With these objectives in mind, our group has been involved in the development of general, chemoselective and easy-to-achieve cobalt-catalyzed cross-couplings of alkyl halides with organometallics. In this account, our contribution to the field of cobalt-catalyzed cross-coupling between alkyl halides and Grignard reagents is disclosed. Our contribution started in 2012, with the cobalt-catalyzed diastereoselective arylation and alkenylation of 1-bromo glycosides. ${ }^{24} \mathrm{We}$ then turned our attention to nitrogen containing heterocycles and a range of iodo-azetidines, iodo-pyrrolidines and iodo-piperidines was successfully reacted with aryl and alkenyl Grignard reagents under cobalt catalysis. ${ }^{25,26}$ Due to their ubiquity in biologically active molecules, $\alpha$-aryl and $\alpha$-alkenyl amides caught our interest and a cobalt-catalyzed cross-coupling between $\alpha$-bromo amides and Grignard reagent was developed. ${ }^{27}$ A slight change in the catalytic system 
allowed an extension of the method to the arylation of $\alpha$-halogeno $\beta$-lactams. ${ }^{28}$ Very recently, the introduction of phenyl bioisosteres consisting of strained cycles such as cyclopropanes or cyclobutanes through cobalt-catalyzed cross-coupling was accomplished. ${ }^{29}$

\section{2- Cobalt-catalyzed arylation of alkyl halides}

\section{2-1 Arylation of $\alpha$-bromo glycosides ${ }^{24}$}

Carbohydrate analogues, such as $C$-aryl glycosides, are of particular interest in medicinal chemistry due to their enhanced resistance to metabolic processes in comparison to $O$-glycosides. ${ }^{30}$ The introduction of anomeric aryl substituents through metal-catalyzed crosscoupling, on readily accessible $\alpha$-bromo glycosides, can appear as a straightforward and versatile strategy. However, side reactions such as $\beta-\mathrm{H}$ or $\beta$-alkoxy eliminations cannot be neglected. In 2011, despite the existing nickel-catalyzed Negishi type cross-coupling between $\alpha$-bromo glycosides and aryl zinc reagent ${ }^{31}$ or the metal-free addition of di-organozinc reagents on $\alpha$ bromo glycosides,${ }^{32}$ there was a need to develop a general method allowing the diastereoselective $\alpha$ - or $\beta$-arylation of glycosides. ${ }^{33}$ Inspired by our previous work on iron-catalyzed alkenylation of alkyl halides, ${ }^{34}$ we focused on the third row metal to induce a catalytic coupling between $O$ acetyl- $\alpha$-bromo-D-mannose $\mathbf{2 . 1}$ and phenylmagnesium bromide. Pleasingly, an efficient and simple catalytic system composed of $\mathrm{CoCl}_{2}$ and TMEDA ( 5 mol \% each) was identified and the desired $\alpha$ - $C$-aryl glycoside $\mathbf{2 . 2}$ was isolated with a good yield (76\%) as a single diastereoisomer (Scheme 6). 


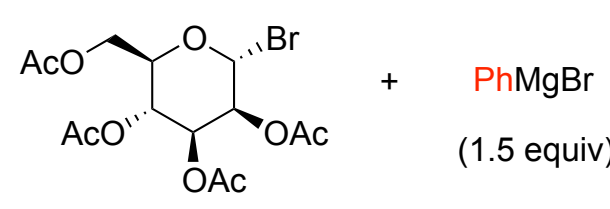

2.1

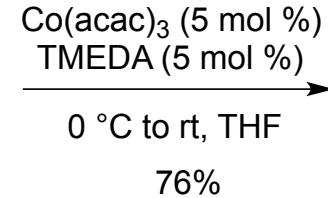

$76 \%$

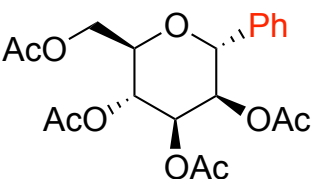

2.2

Scheme 6. Cobalt-catalyzed arylation of $O$-acetyl- $\alpha$-bromo-D-mannose.

With these optimized conditions in hand, the scope of the reaction was evaluated. Various electron-rich and electron-poor Grignard reagents were successfully reacted with the 2-bromomannose derivative delivering the coupling products with yields up to $83 \%$ and excellent diastereoselectivities in favor of the $\alpha$-isomer. However, one limitation was encountered when using sterically hindered Grignard reagents, which revealed reluctant to the cross-coupling (Scheme 7).

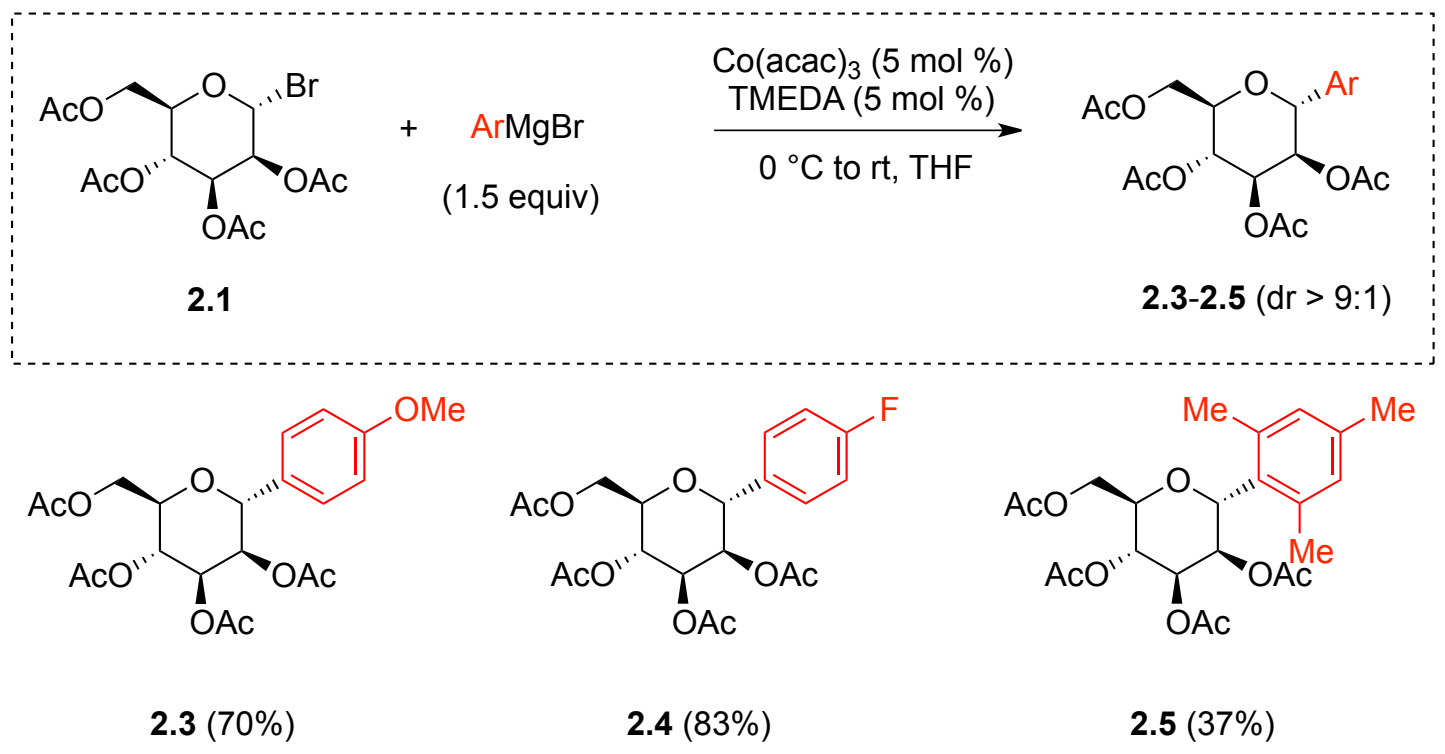

Scheme 7. Arylation of $O$-acetyl $\alpha$-bromo-D-mannose using different aryl Grignard reagents.

Similar results were obtained with a 2-bromo-galactose derivative both in terms of yield and diastereoselectivity of the coupling reaction. However, when $O$-acetyl $\alpha$-bromo- $D$-glucose was 
reacted with aryl Grignard reagents, in the presence of the developed catalytic system, a lower diastereoselectivity was observed, albeit again in favor of the $\alpha$-diastereomer (Scheme 8).

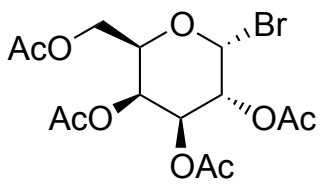

2.6

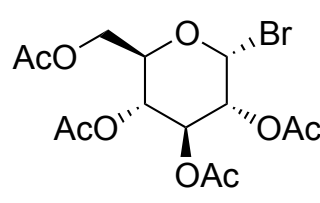

2.8
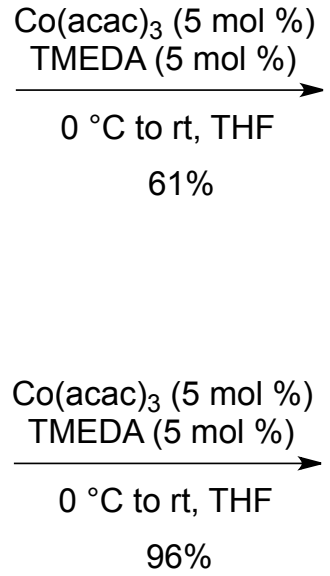

(1.5 equiv)

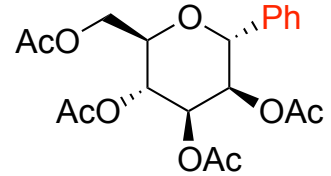

$2.7(d r>9: 1)$

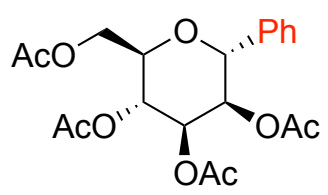

$2.9(d r=3: 1)$

Scheme 8. Arylation of 2-bromo-galactose and 2-bromo-glucose derivatives with phenylmagnesium bromide.

Several evidences in favor of a radical intermediate, during the cobalt-catalyzed cross-couplings, were reported in the literature. ${ }^{35}$ In the case of the arylation of $\alpha$-bromo glycosides, the putative formation of an anomeric C-radical may account for the diastereoselectivity in favor of the $\alpha$-diastereomer. ${ }^{36}$ To confirm this hypothesis, the radical clock $\mathbf{2 . 1 0}$ was prepared and involved in the cobalt-catalyzed cross-coupling with phenylmagnesium bromide. As expected, the bicyclic product 2.11 resulting from a 5-exo-trig cyclization of an anomeric radical, followed by a crosscoupling, was isolated with a yield of $88 \% .^{37}$ This result is in favor of the formation of radical species before the reductive elimination step (Scheme 9). 


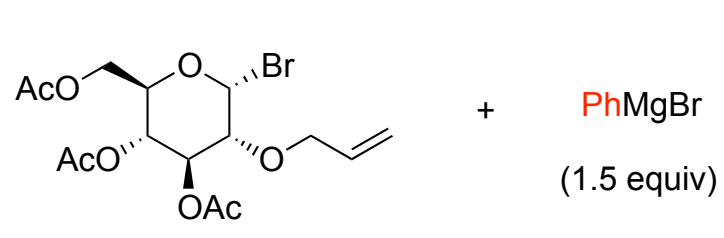

2.10

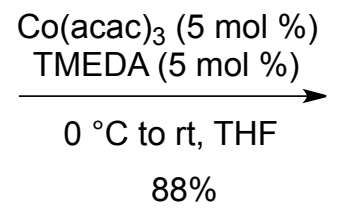

$88 \%$

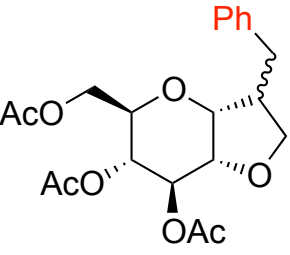

$2.11(\mathrm{dr}=1: 1)$

Scheme 9. Evidence in favor of a radical intermediate before the coupling.

\section{2-2 Arylation of iodo- $N$-heterocyles}

Encouraged by these promising results related to the arylation of glycosides derivatives, we then decided to focus on the functionalization of other key heterocyclic building blocks of interest for medicinal chemists, e.g. saturated $N$-heterocycles. Indeed, according to a classification of heterocycles present in pharmaceuticals and reported in 2014, piperidines and pyrrolidines are among the top ten frameworks present in FDA approved drugs (respectively third and eighth position).$^{38}$ Even though absent of the classification, azetidines raise an exponential interest among the medicinal chemists. ${ }^{39}$ Again, metal-catalyzed functionalization of these heterocycles through cross-coupling can be considered as an appealing flexible strategy to generate libraries of attractive molecules. With this idea in mind, in 2014, we embarked in a new catalysis project dedicated to earth-abundant metal catalyzed iodo- $N$-heterocycles arylation. ${ }^{25}$ The optimization study was conducted for the reaction between the $N$-Boc 3-iodo-azetidine and phenylmagnesium bromide. Among the catalytic systems screened, the use of $\mathrm{CoCl}_{2}$ associated with $1,2-N, N, N^{\prime}, N^{\prime}-$ tetramethylcyclohexyldiamine (TMCD) gave the best result, ${ }^{40}$ allowing the isolation of the coupling product in excellent yield (90\%) (Scheme 10). 


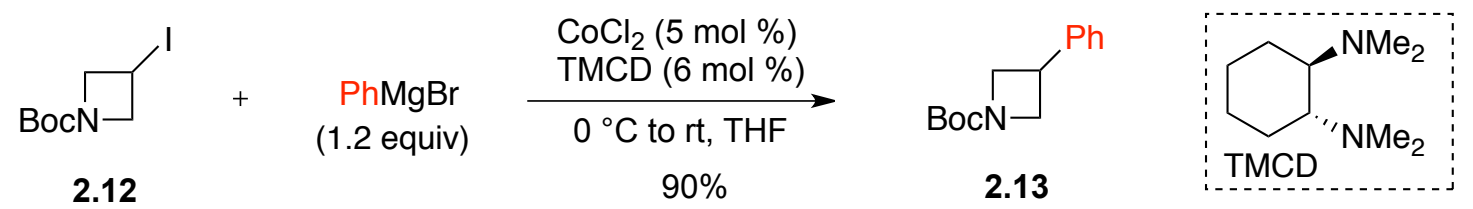

Scheme 10. Cobalt-catalyzed arylation of $N$-Boc 3-iodo-azetidine with phenylmagnesium bromide.

Under these conditions, a panel of aryl Grignard reagents was efficiently reacted with the iodo-azetidine and no influence of the electronic nature of the organometallic was noticed. Interestingly, the coupling was not sensitive to steric hindrance as the $o$-tolylmagnesium bromide was reacted successfully to produce the desired product in $79 \%$ yield. The reaction proved chemoselective as a carbonate was tolerated on the Grignard reagent. Pleasingly, two heteroaromatics could be introduced on the azetidine ring with excellent yields (90\% for the pyridine ring and $91 \%$ for the thiophene moiety) (Scheme 11). 


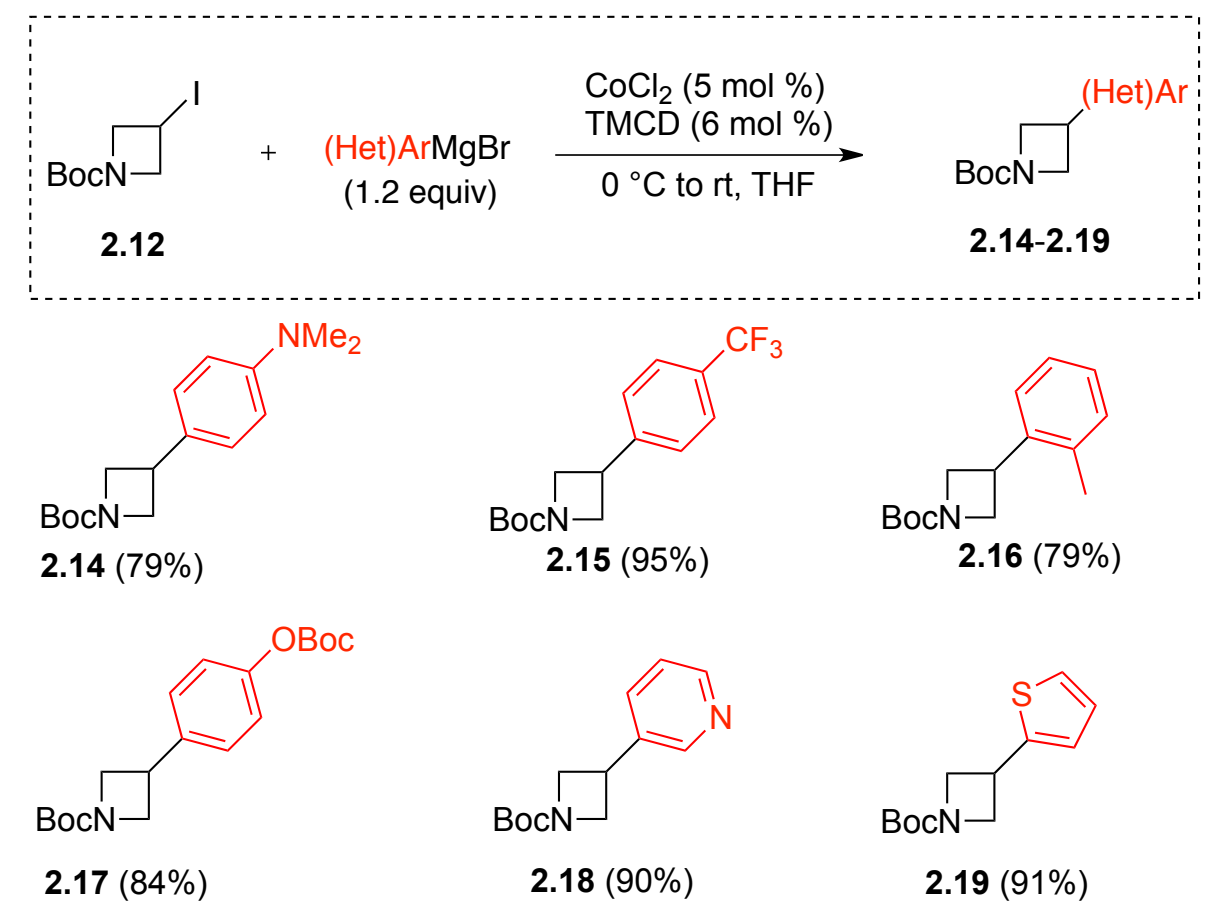

Scheme 11. Arylation of $N$-Boc 3-iodo-azetidine using a range of (hetero)aryl Grignard reagents.

The reactivity of 2,3-disubstituted iodo-azetidine was then investigated and, when $\mathbf{2 . 2 0}$ was reacted with phenylmagnesium bromide under the previous conditions, the coupling product was isolated in $93 \%$ yield, confirming the low sensitivity of the reaction to steric hindrance. It is worth noting that the arylation proceeded with an evolution of the diastereomeric ratio: starting from a 75:25 cis/trans ratio for the iodide resulted in the formation of the arylated product in a 13:87 cis/trans ratio. This stereoselectivity could come from the generation of a radical intermediate during the process, inducing the loss of the initial stereochemical information (Scheme 12). 


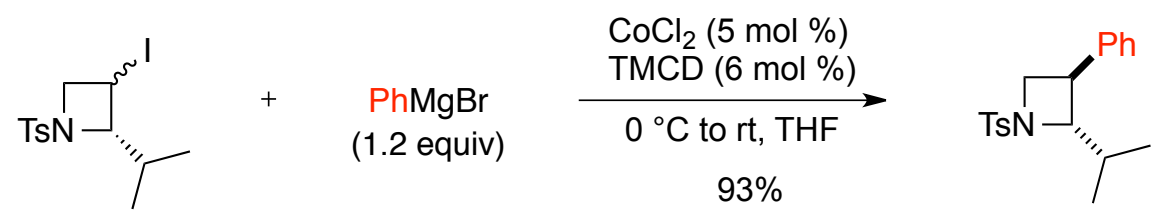

2.20

$($ cis/trans $=75: 25)$

2.21

$($ cis/trans $=13: 87)$

Scheme 12. Cross-coupling between a disubstituted iodo-azetidine and phenylmagnesium bromide and evolution of the cis/trans ratio.

The method was successfully extended to the arylation of 3-iodo pyrrolidines, which were transformed to their arylated counterparts with yields ranging from $74 \%$ to $93 \%$ (Scheme 13).
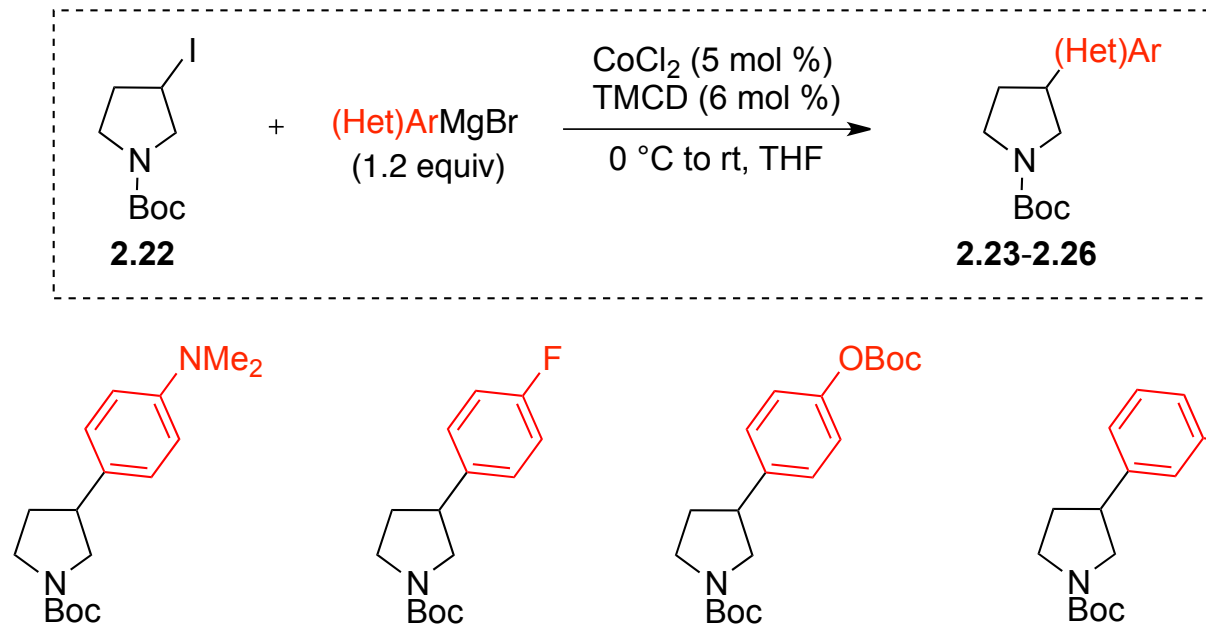

$2.23(74 \%)$

$2.24(85 \%)$

$2.25(93 \%)$

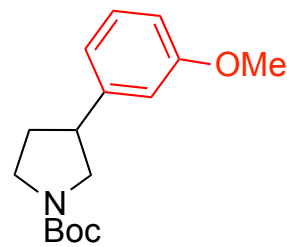

$2.26(84 \%)$

Scheme 13. Access to a panel of 3-aryl pyrrolidines through cobalt-catalyzed cross-coupling.

The exclusive formation of the bicyclic product $\mathbf{2 . 2 8}$ from the radical clock $\mathbf{2 . 2 7}$ confirmed the formation of radical intermediates during the cross-coupling (Scheme 14). 


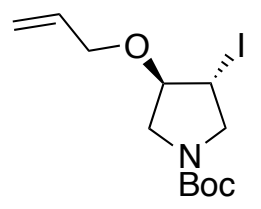

2.27

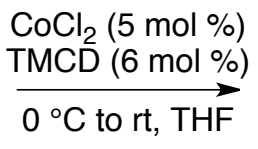

$80 \%$

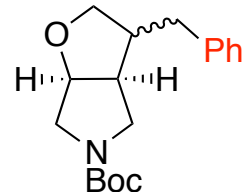

$2.28(\mathrm{dr}=80: 20)$

Scheme 14. Cross-coupling between a radical clock and phenylmagnesium bromide highlighting the formation of a radical species.

To complete our study on iodo- $N$-heterocycles arylation, the reactivity of 3- and 4-iodo piperidines was evaluated..$^{25,26}$ If very similar results were obtained for 3-iodo azetidines, 3-iodo pyrrolidines and 4-iodo piperidines, 3-iodo piperidines revealed more prone to side reactions and a decrease of the temperature, to $-10{ }^{\circ} \mathrm{C}$, was essential to reach high yields in the coupling products. These slightly modified conditions allowed the access to a variety of 3-aryl piperidines that constitute an important pharmacophore (Scheme 15).

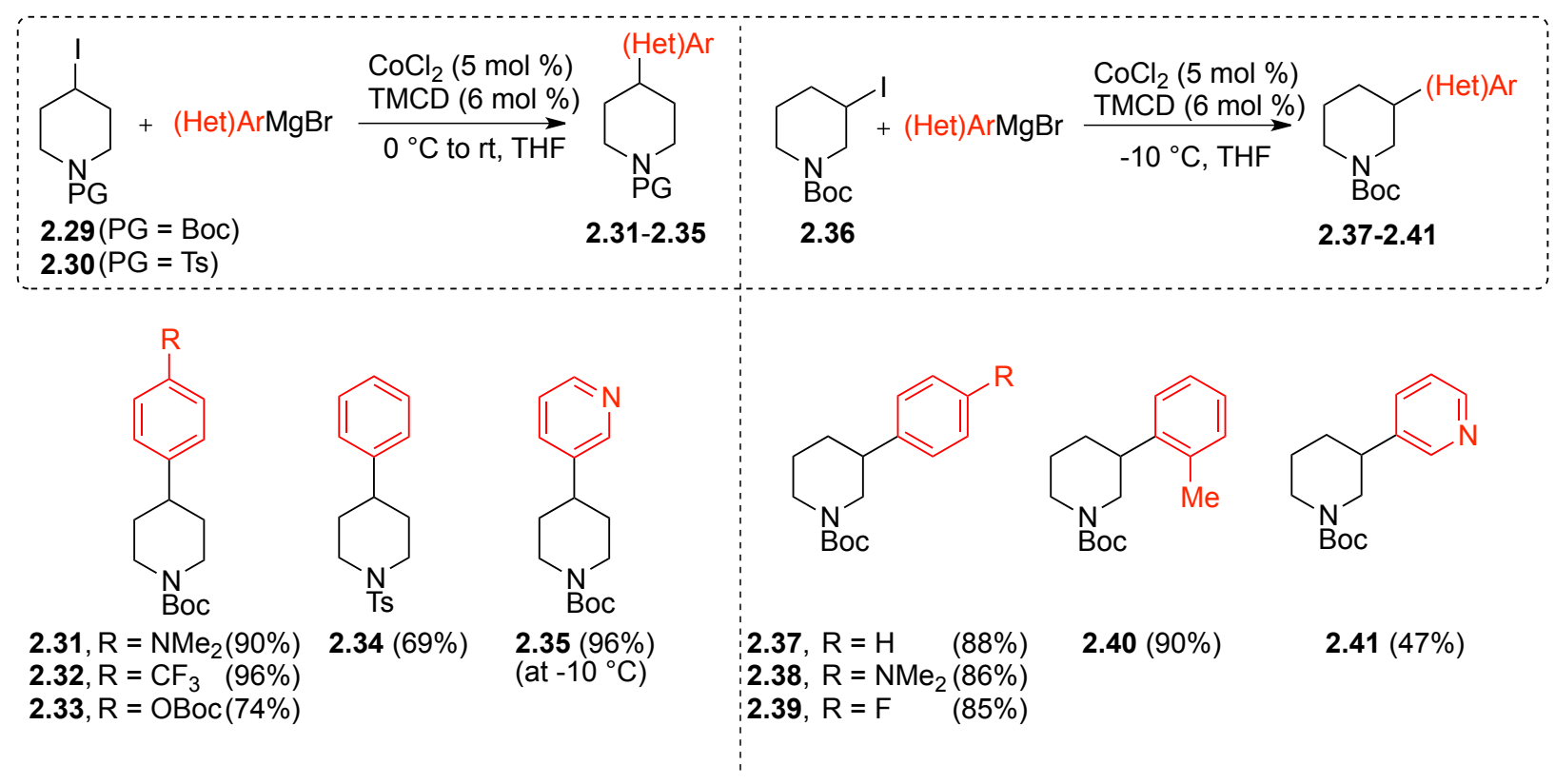

Scheme 15. Cobalt-catalyzed arylation of 3-iodo and 4-iodo piperidines. 
Notably, the developed cobalt-catalyzed cross-coupling was successfully used as a key step in a short and efficient synthesis of ( \pm )-preclamol, an antipsychotic agent (Scheme 16).

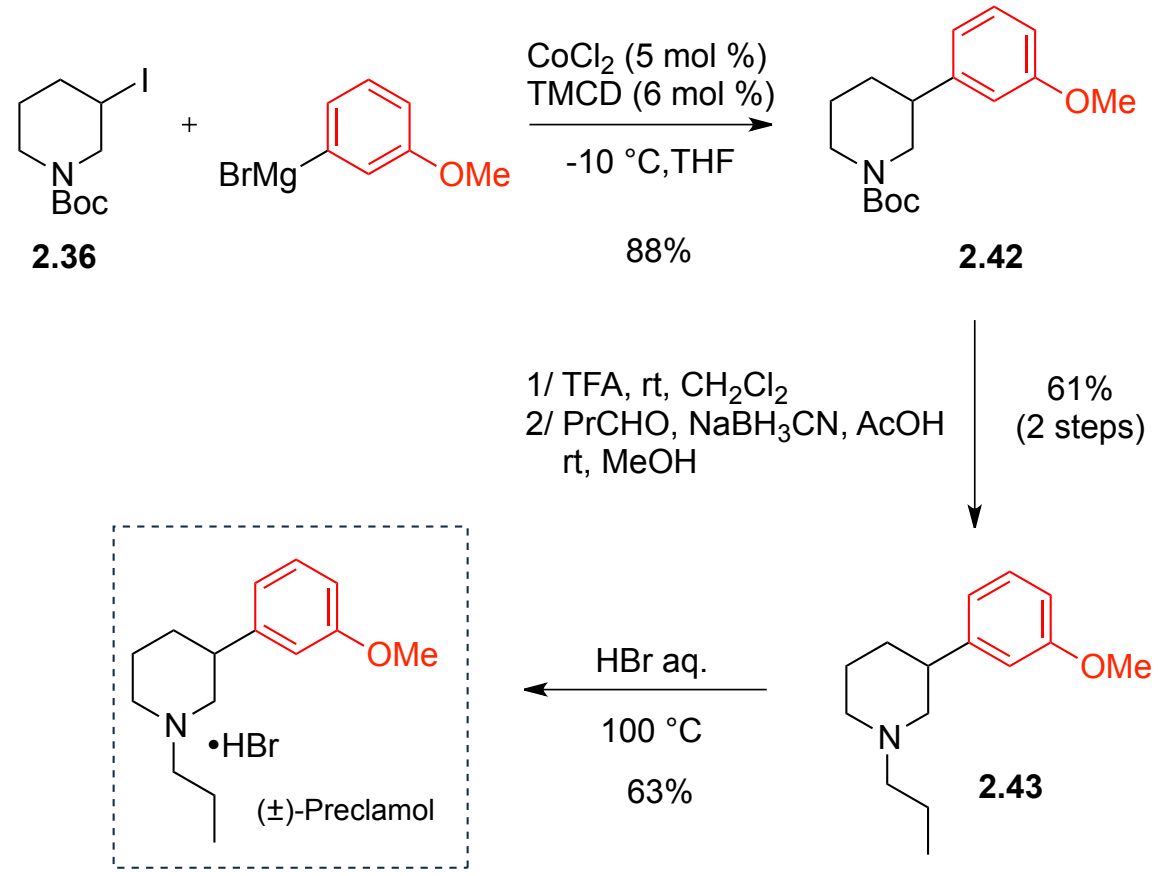

Scheme 16. Application of the coupling to a short synthesis of ( \pm )-preclamol.

Once again, the reaction of the radical clock $\mathbf{2 . 4 4}$ with phenylmagnesium bromide highlighted the transient formation of radicals during the coupling. Interestingly, when 3-iodo piperidine 2.46, which possesses an additional carbon in the unsaturated pendant chain, was reacted under the optimized conditions, the direct coupling product was exclusively formed. Taken together, these results may afford an estimation of the cross-coupling rate that may be comprise in between a 5-exo-trig and a 6-exo-trig rate (Scheme 17). 


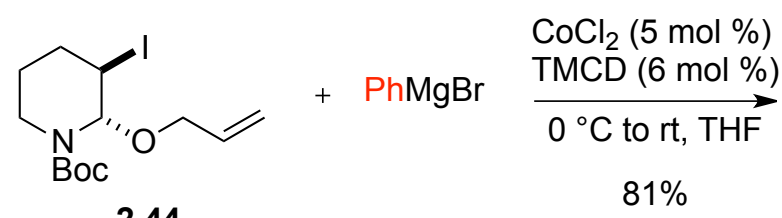

2.44

(cis/trans $=2: 98)$

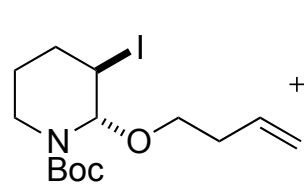

2.46

$($ cis/trans $=30: 70)$

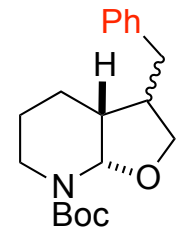

2.45

$(d r=80: 20)$

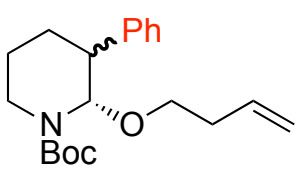

2.47

$(\mathrm{dr}=60: 40)$

Scheme 17. Cobalt-catalyzed cross-coupling between radical clocks and phenylmagnesium bromide.

2-3 Arylation of $\alpha$-bromo amides and $\alpha$-bromo lactams ${ }^{27,28}$

$\alpha$-Aryl amides are ubiquitous motif present in a variety of bioactive molecules such as atenolol,,${ }^{41}$ used in the treatment of cardiovascular diseases, or almorexant ${ }^{42}$ that can prevent insomnia. In addition, there are analogues of nonsteroidal anti-inflammatory drugs incorporating an $\alpha$-aryl carboxylic acid pharmacophore. To access these $\alpha$-aryl amides, a flexible route based on the cobalt-catalyzed arylation of $\alpha$-bromo amides with Grignard reagents was investigated. ${ }^{43}$ Pleasingly, the association of $\mathrm{CoCl}_{2}$ with the diphosphine ligand, Xantphos, allowed the coupling of a range of aryl Grignard reagents with several $\alpha$-bromo amides. ${ }^{27}$ The reaction was compatible with electron-rich and electron-withdrawing groups on the phenyl ring of the Grignard reagent but revealed sensitive to steric hindrance. Different substituents were tolerated on the nitrogen atom that could also be embedded in a cycle (Scheme 18). 


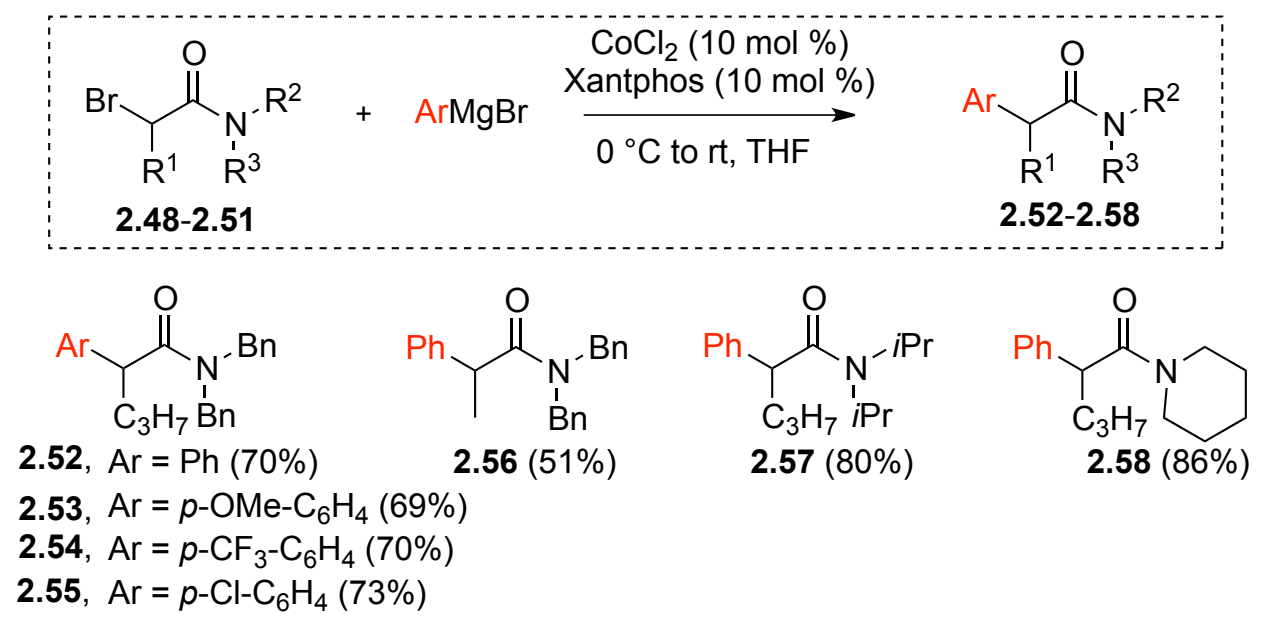

Scheme 18. Cobalt-catalyzed arylation of $\alpha$-bromo amides with aryl Grignard reagents.

The reaction was extended to the arylation of 5-membered and 6-membered ring $\alpha$-bromo lactams delivering the corresponding coupling products albeit with moderate isolated yields (51\% and 56\% respectively) (Scheme 19).
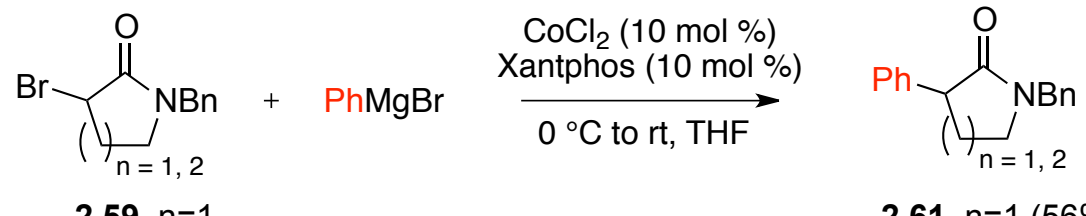

2.59, $n=1$

2.61, $n=1(56 \%)$

2.60, $n=2$

2.62, $n=2(51 \%)$

Scheme 19. Cobalt-catalyzed arylation of 5-membered and 6-membered ring $\alpha$-bromo lactams. Reproduced with permission from ref. 27. Copyright 2017 American Chemical Society.

In a subsequent study, the catalytic system was slightly modified to allow the extension of the coupling reaction to the arylation of $\alpha$-halo $\beta$-lactams.$^{28}$ In this case, the use of a diamine ligand (TMEDA) instead of a diphosphine favored the formation of the coupling product. When $p$-tolylmagnesium bromide was used, a range of trans-3-bromo 4-aryl- $\beta$-lactam were efficiently arylated with yields ranging from $64 \%$ to $86 \%$ (Scheme 20 ). 


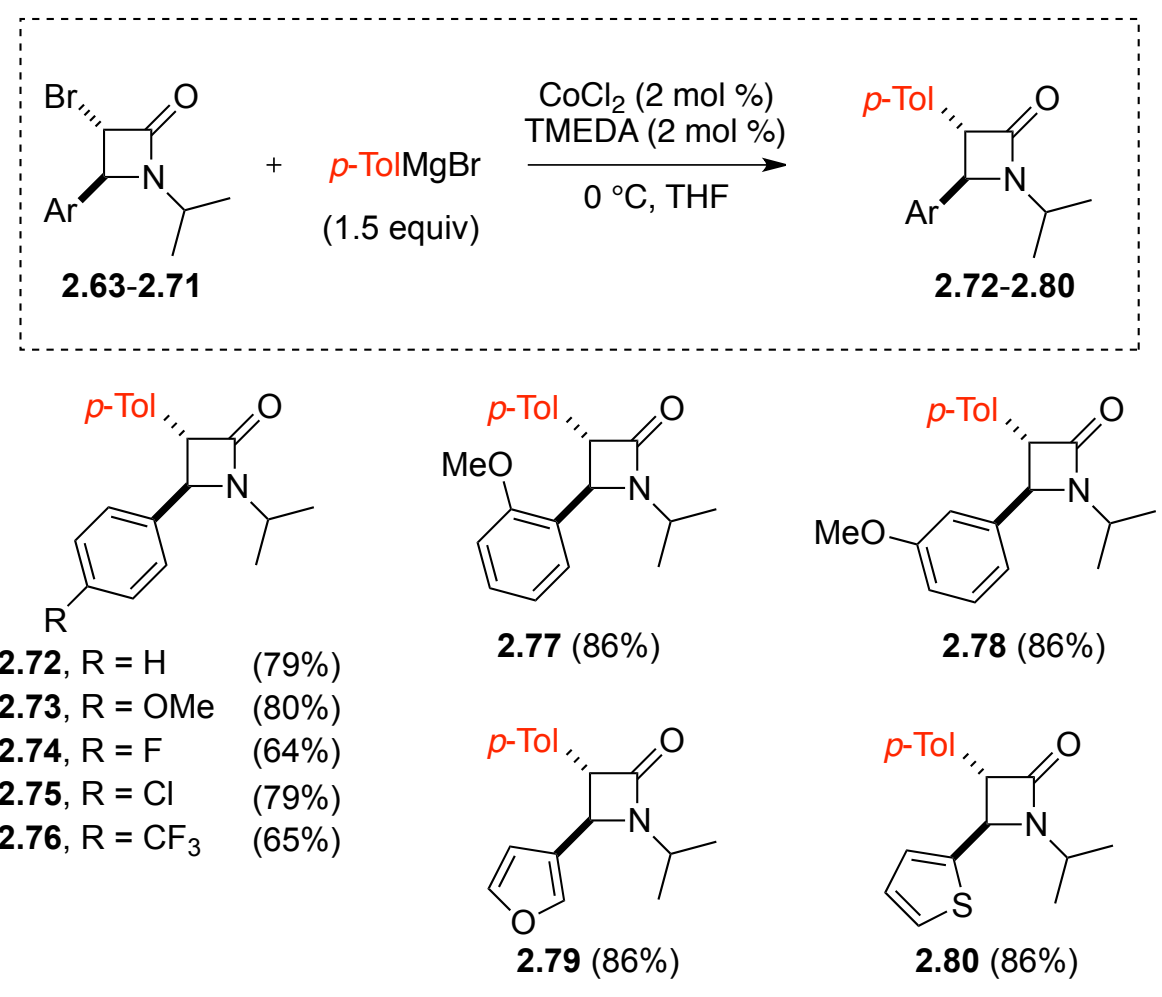

Scheme 20. Cobalt-catalyzed arylation of trans-3-bromo 4-aryl- $\beta$-lactams with $p$-tolylmagnesium bromide.

Electron-rich as well as electron-poor aryl Grignard reagents were successfully used delivering the coupling products with moderate to good yields (Scheme 21). ${ }^{44}$ 


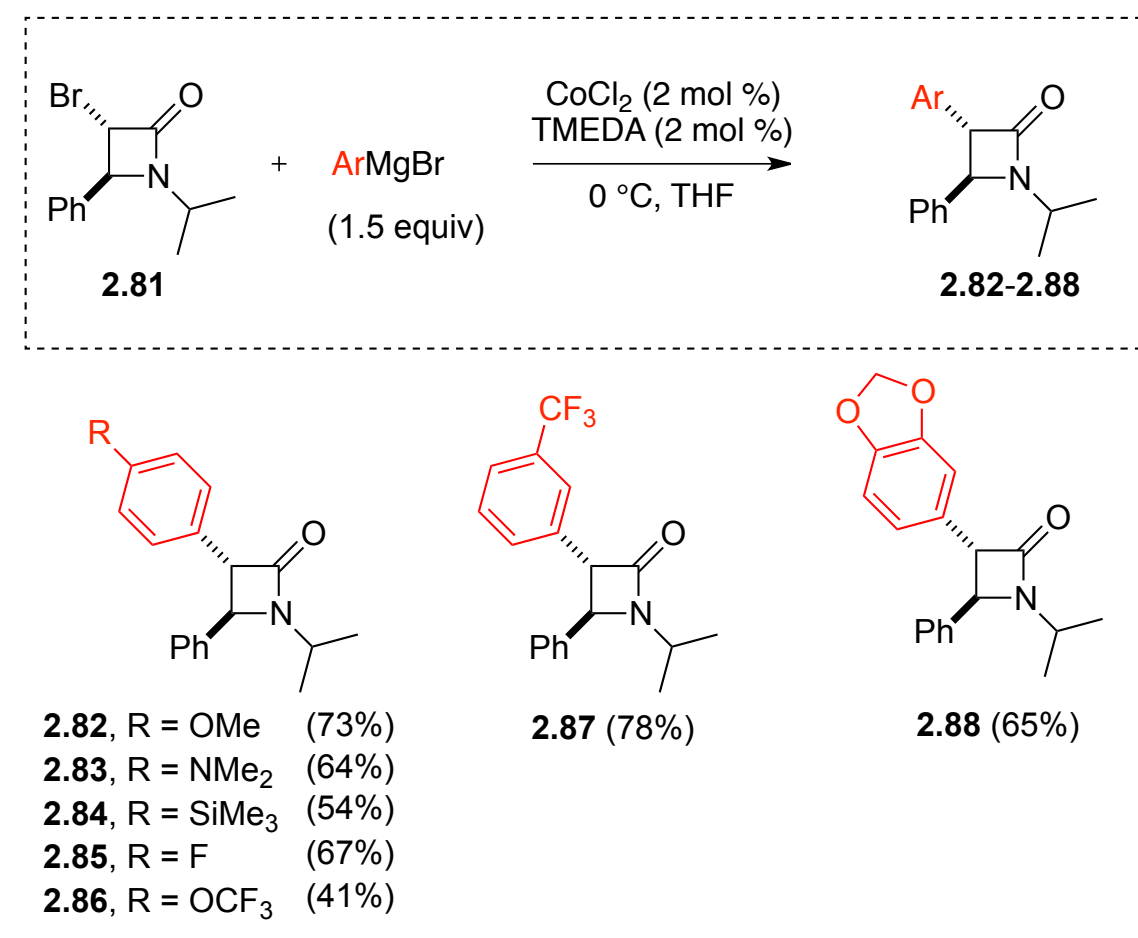

Scheme 21. Arylation of $\alpha$-bromo $\beta$-lactam $\mathbf{2 . 8 1}$ using a range of aryl Grignard reagents.

Pleasingly, the $N-p$-methoxybenzyl (PMB) protecting group was tolerated under the optimized conditions furnishing a $\beta$-lactam that can be deprotected in a subsequent step using ceriumammonium nitrate (CAN) (Scheme 22). ${ }^{45}$

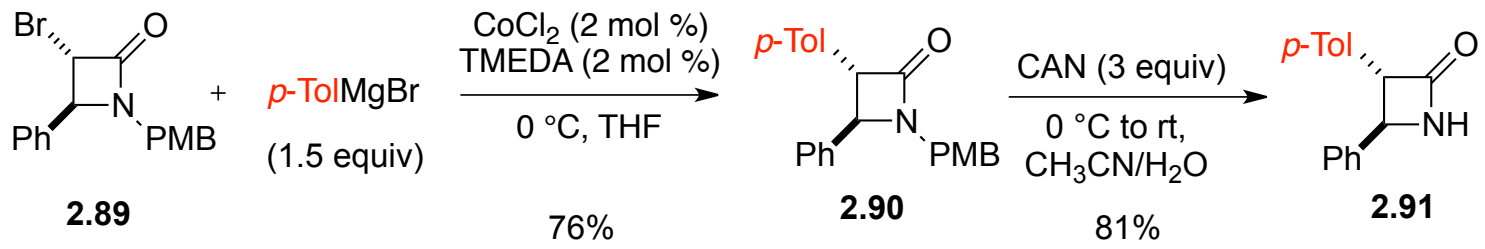

Scheme 22. Cross-coupling of $N$-PMB bromo $\beta$-lactam and subsequent deprotection of the nitrogen atom.

3- Cobalt-catalyzed alkenylation of alkyl halides 
Interestingly, most of the reported catalytic systems identified for the arylation of alkyl halides could be used in alkenylation of alkyl halides, demonstrating the generality of the coupling reaction.

\section{3-1 Alkenylation of $\alpha$-bromo glycosides ${ }^{24}$}

The cobalt catalyzed arylation of 2-bromo glycosides was successfully extended to the alkenylation of similar substrates delivering the corresponding $\alpha$-C-vinyl glycosides with satisfying yields. For example, in the presence of 2-methyl-1-propenylmagnesium bromide, the $\alpha$-bromo mannose derivative was transformed to the coupling product with a yield of $66 \%$ and an excellent diastereoselectivity in favor of the $\alpha$-isomer. Starting from a $\alpha$-bromo galactose derivative, a similar result was obtained while using a $\alpha$-bromo glucose derivative led to the coupling product with a good yield but with poor diastereoselectivity (Scheme 23). It is worth mentioning that one limitation was encountered when vinylmagnesium bromide was used as no reaction occurred when reacted with the $\alpha$-bromo mannose tetracetate (not shown).

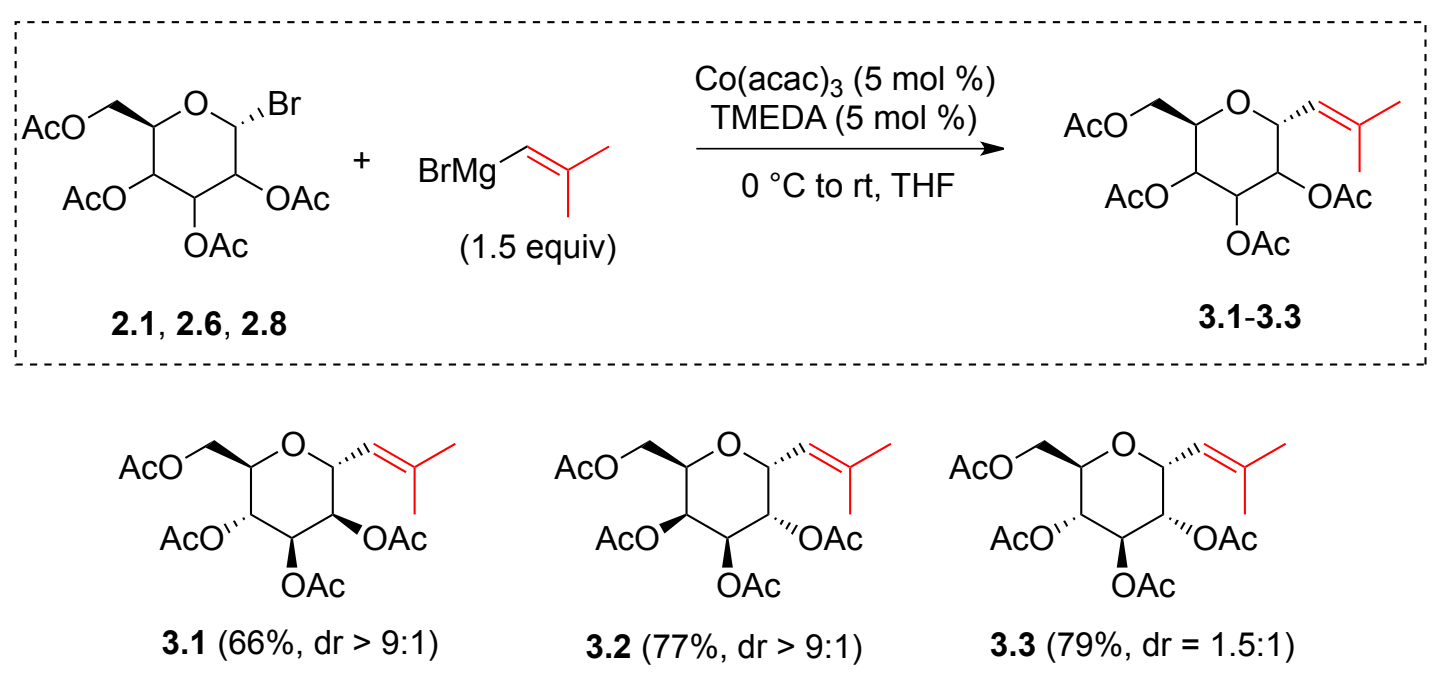

Scheme 23. Cobalt-catalyzed alkenylation of $\alpha$-bromo glycosides using Grignard reagents. 


\section{3-2 Alkenylation of 4-iodo piperidines ${ }^{26}$}

The alkenylation of 4-iodo-piperidines with Grignard reagents was investigated and it was shown that, compared to the arylation, a decrease of the temperature to $-10{ }^{\circ} \mathrm{C}$ was necessary to selectively obtain the desired coupling product. Indeed, when $N$-Boc 4-iodo piperidine $\mathbf{2 . 2 9}$ was reacted at $0{ }^{\circ} \mathrm{C}$ to room temperature with 2-methyl-1-propenylmagnesium bromide in the presence of the $\mathrm{CoCl}_{2} / \mathrm{TMCD}$ catalytic system, the alkenyl piperidine 3.4 was obtained in a modest $52 \%$ yield due to the formation of the elimination product $\mathbf{3 . 5}$ in a significant amount (3.4 $/ 3.5$ ratio $=78: 22$ on the crude). Decreasing the temperature to $-10{ }^{\circ} \mathrm{C}$ was the key to obtain the targeted product with a satisfying yield of $70 \%$ (Scheme 24). Again, vinylmagnesium bromide was unable to react under these conditions.

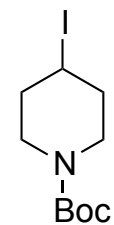

2.29

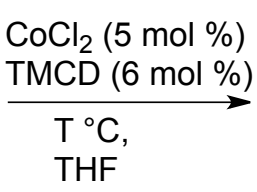

(2 equiv)

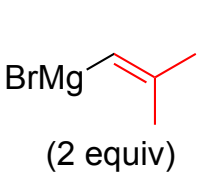

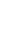

(

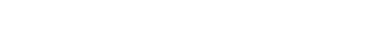


catalytic system composed of $\mathrm{CoCl}_{2}$ and Xantphos (10 mol \% each) successfully promoted this alkenylation reaction. A range of alkenylmagnesium bromides including vinylmagnesium bromide was coupled to $\alpha$-bromo amide $\mathbf{2 . 4 8}$, delivering the corresponding $\beta, \gamma$-unsaturated amides with yields ranging from $63 \%$ to $89 \%$. $\alpha, \beta$-Unsaturated amides resulting from an isomerization of the double bond were never observed (Scheme 25). ${ }^{47}$

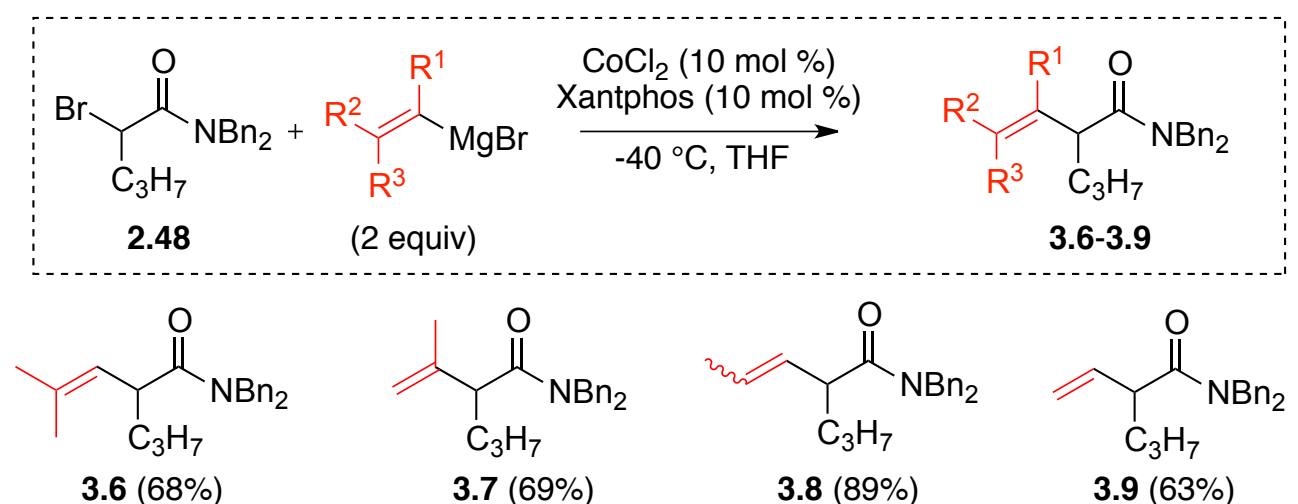

Scheme 25. Cobalt-catalyzed alkenylation of $\alpha$-bromo amide $\mathbf{2 . 4 8}$.

4- Cobalt-catalyzed cross-coupling between alkyl halides and cyclopropylmagnesium and cyclobutylmagnesium bromides ${ }^{29}$

4-1 Cross-coupling between cyclopropyl magnesium bromide and alkyl halides

Over the last decade, a growing interest has been devoted to strained carbocycles such as cyclopropanes or cyclobutanes in medicinal chemistry. ${ }^{48,49}$ Indeed, in bioactive molecules, these small rings can be considered as surrogates of phenyl rings as these latter can cause problems of pharmacokinetics, toxicity or solubility..$^{50,51}$ As a consequence, developing a flexible method allowing the introduction of cyclopropyl/cyclobutyl rings on alkyl halides that can be compatible with late-stage functionalization is of high interest. ${ }^{52}$ Encouraged by our results obtained in cobalt-catalyzed alkenylation of alkyl halides and considering that cyclopropylmagnesium 
bromide is not so far from an alkenylmagnesium bromide, we investigated the cyclopropanation of primary iodide 4.1. After an optimization study, a simple system composed of the nonhygroscopic $\mathrm{Co}(\mathrm{acac})_{2}(3.5 \mathrm{~mol} \%)$ and TMEDA (1 equiv) was identified. Under these conditions, the expected coupling product 4.2 was selectively obtained with no traces of eliminated nor dehalogenated products (Scheme 26).

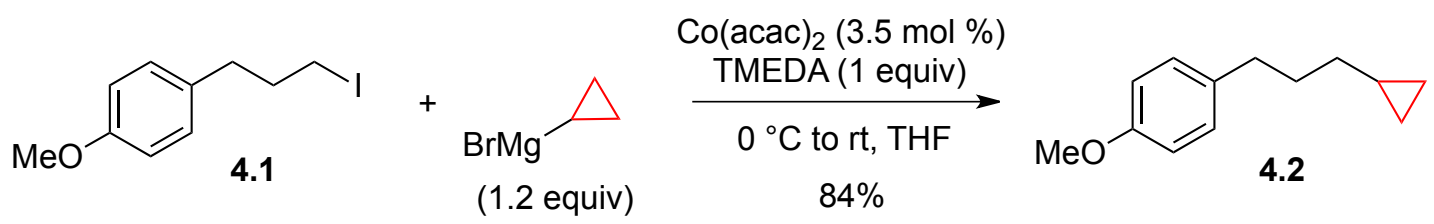

Scheme 26. Cobalt-catalyzed cyclopropanation of primary alkyl iodide 4.1.

A panel of primary iodides was then successfully transformed into the monosubstituted cyclopropanes. The reaction tolerated the presence of benzyl and silyl ethers and, more interestingly, a complete selectivity towards the alkyl iodide was observed in the presence of an aryl bromide allowing further coupling reactions. Electrophilic functions that could be prone to Grignard addition such as ester or nitrile were compatible with the cross-coupling conditions, however in the case of a nitrile, a gem-dimethyl group in the $\alpha$ position was mandatory to avoid side reactions (Scheme 27). 


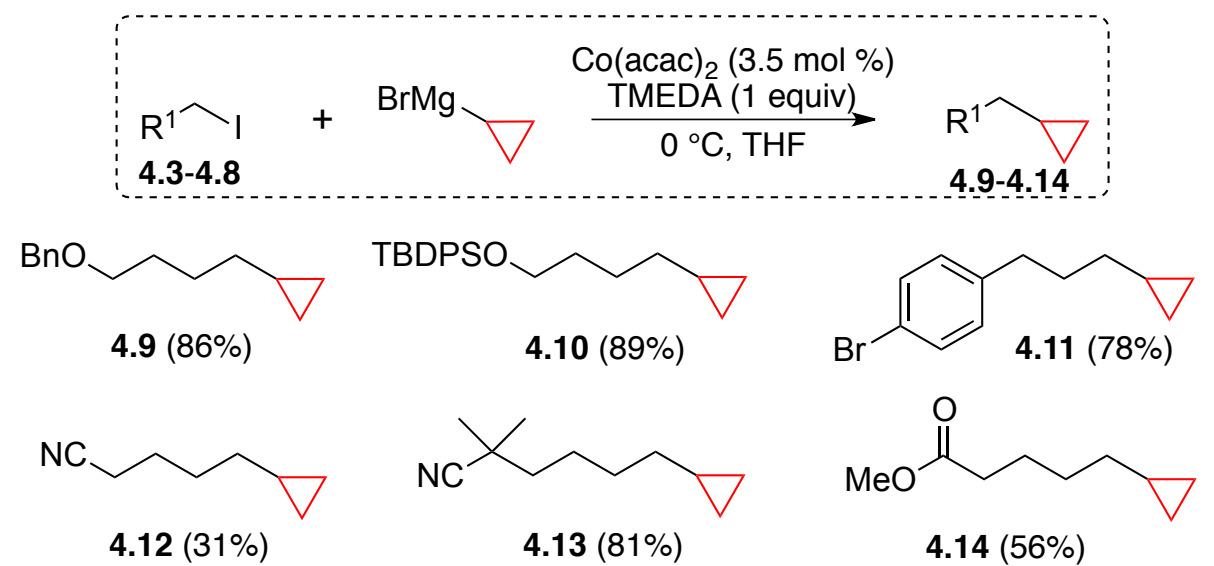

Scheme 27. Cobalt-catalyzed cross-coupling between primary alkyl iodides and cyclopropylmagnesium bromide. Reproduced with permission from ref. 29. Copyright 2019 American Chemical Society.

Pleasingly, the reaction was extended to the more challenging secondary alkyl iodides partners. Acyclic secondary alkyl iodides as well as iodo $N$-heterocycles were converted to their cyclopropanyl derivatives with good to excellent yields (Scheme 28). The introduction of a strain cyclopropane ring on valuable scaffolds such as piperidines, pyrrolidines or azetidines could be of high interest for medicinal chemists. 


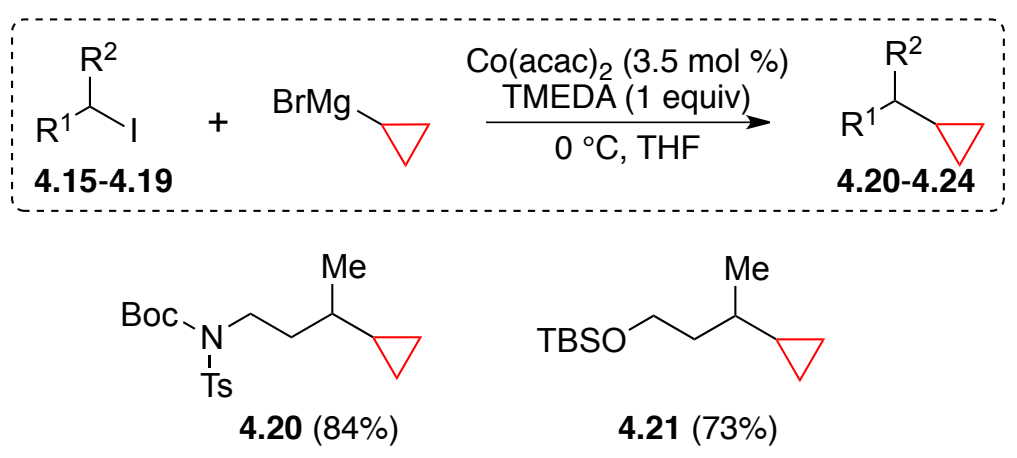

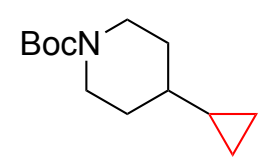

$4.22(96 \%)$

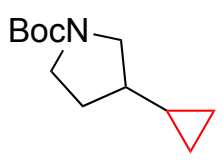

$4.23(86 \%)$

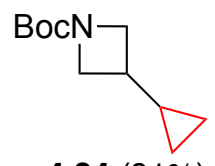

$4.24(91 \%)$

Scheme 28. Cobalt-catalyzed cross-coupling between secondary alkyl iodides and cyclopropylmagnesium bromide.

From a mechanistic point of view, the formation of radical species was hypothesized and verified. Indeed, when the two diastereomeric secondary iodides $4.25 \mathrm{a}$ and $4.25 \mathrm{~b}$ were reacted separately with cyclopropylmagnesium bromide in the presence of the cobalt catalytic system $\left[\mathrm{Co}(\mathrm{acac})_{2} / \mathrm{TMEDA}, \mathrm{THF}, 0^{\circ} \mathrm{C}\right]$, the same trans coupling product $\mathbf{4 . 2 6}$ was obtained, indicating a diastereo-convergence of the cross-coupling (Scheme 29).

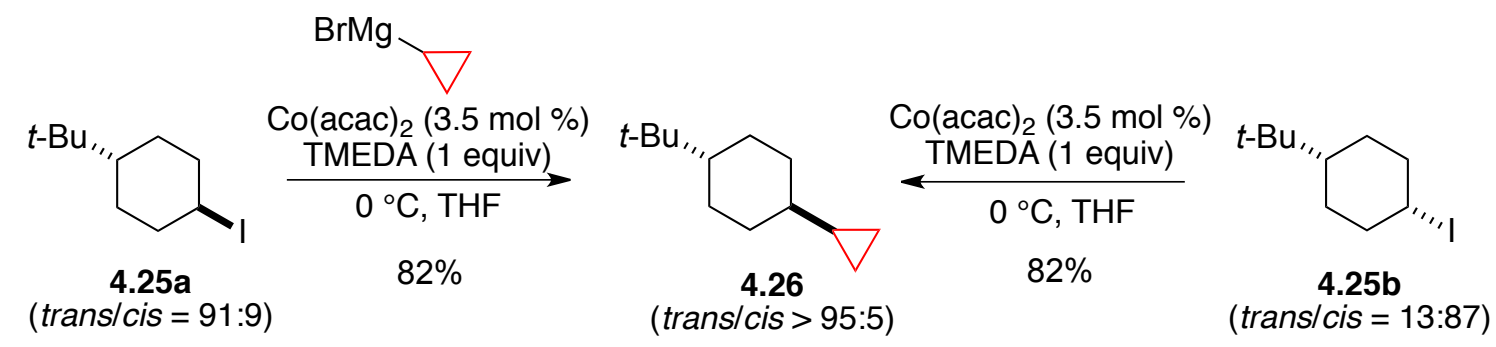

Scheme 29. Diastereo-convergence of the cross-coupling between alkyl iodides and cyclopropylmagnesium bromide. 
In addition, when reacted under the reported conditions, the radical clock $\mathbf{2 . 4 4}$ exclusively led to the tricyclic compound 4.27 that could result from a 5-exo-trig cyclization/cross-coupling sequence (Scheme 30).

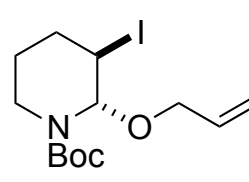

2.44

(cis/trans $=15: 85)$

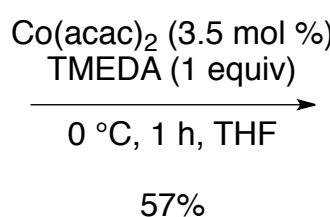

$57 \%$

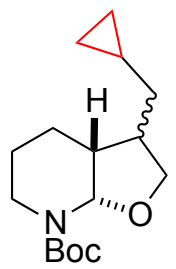

4.27

$(d r=80: 20)$

Scheme 30. Sequential 5-exo-trig cyclization/cross-coupling reaction using 3-iodo piperidine 2.44 .

The same catalytic system was shown to promote efficiently the introduction of a cyclobutane on primary and secondary alkyl iodides (Scheme 31$)$.

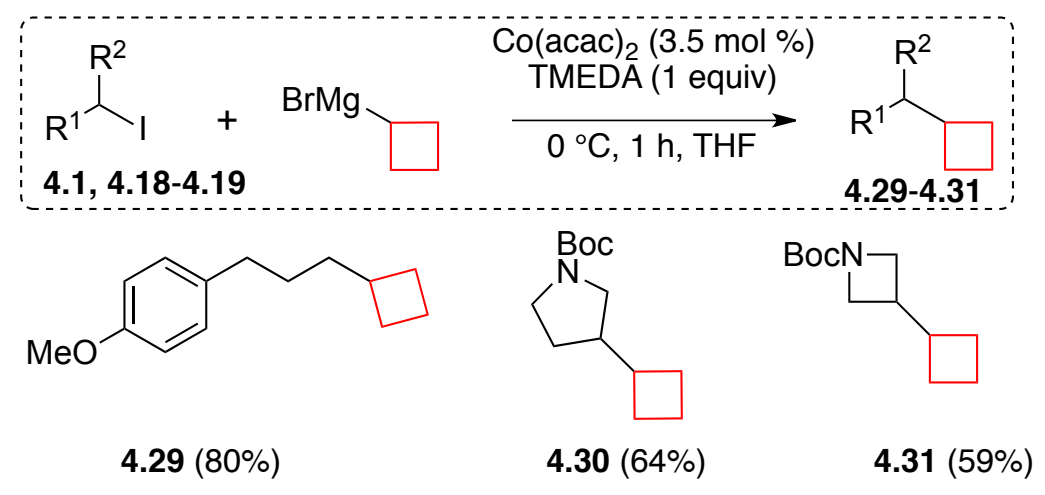

Scheme 31. Cobalt-catalyzed cross-coupling between alkyl iodides and cyclobutylmagnesium bromide. Reproduced with permission from ref. 29. Copyright 2019 American Chemical Society.

5- Mechanism considerations 
Despite the abundance of the literature reports on cobalt-catalyzed cross-couplings, mechanistic studies are very scarce.$^{53}$ As a consequence a precise mechanism, including the identification of all the elementary steps and the exact cobalt species participating to the coupling, has not been established yet. If it is unanimously accepted that starting $\mathrm{Co}(\mathrm{II})$ or $\mathrm{Co}(\mathrm{III})$ complexes are only pre-catalysts that need to be reduced to enter the catalytic cycle, the oxidation degree of the active catalyst $[\mathrm{Co}(0)$ or $\mathrm{Co}(\mathrm{I})]$ remains open to debate. Similarly, the exact role of the ligand has not been completely elucidated. If the ligand is supposed to stabilize low-valent cobalt species, the need of ligand modifications when changing the nature of the substrate and/or the Grignard reagent is not well understood. The formation of radical species during the cross-coupling has been frequently evidenced and the existence of Single Electron Transfer (SET) has thus been hypothesized.

In 2019, Koszinowski et al. published a mechanistic study related to cobalt/phosphine catalyzed cross-coupling using mass spectrometry. They confirm the reduction of Co(II) precatalysts into low-valent cobalt species that are able to transfer one electron to an alkyl bromide, resulting in the formation of an alkyl radical. After combination of this radical and a cobalt complex followed by reductive elimination, the coupling product is released.

Our studies also provide the evidence for alkyl radicals formation during cobalt-catalyzed crosscouplings. Whatever the catalytic system involved, the cyclization of radical clocks prior to coupling and/or the diastereo-convergence of the coupling are in favor of the existence of single electron transfer processes. However, the true active catalyst remains unknown as well as the order of the elementary steps. Based on literature reports, the following mechanism can be proposed. An initial reduction of the Co(II) pre-catalyst by the Grignard reagent would furnish the active catalytic species. The oxidation state of this catalyst remains under debate and $\operatorname{Co}(0)$ 
or $\mathrm{Co}(\mathrm{I})$ may be involved in the catalytic cycle, probably depending on the substrates. The lowvalent cobalt species would be then able to transfer an electron to the alkyl halide providing a radical-anion that could then dissociate into an alkyl radical $\left(\mathrm{R}^{\prime \bullet}\right)$ and an halide anion $\left(\mathrm{X}^{-}\right)$. $\mathrm{A}$ transmetalation between the Grignard reagent $\mathrm{RMgBr}$ and the cationic cobalt species would release the cobalt complex $\left[\mathrm{L}_{\mathrm{n}} \mathrm{Co}(\mathrm{n}+1) \mathrm{R}\right]$ that would recombine with the alkyl radical to form the heteroleptic complex $\left[\mathrm{L}_{\mathrm{n}} \mathrm{Co}(\mathrm{n}+2) \mathrm{RR}\right.$ ']. Finally, a reductive elimination would deliver the coupling product and regenerate the active catalyst (Scheme 32).

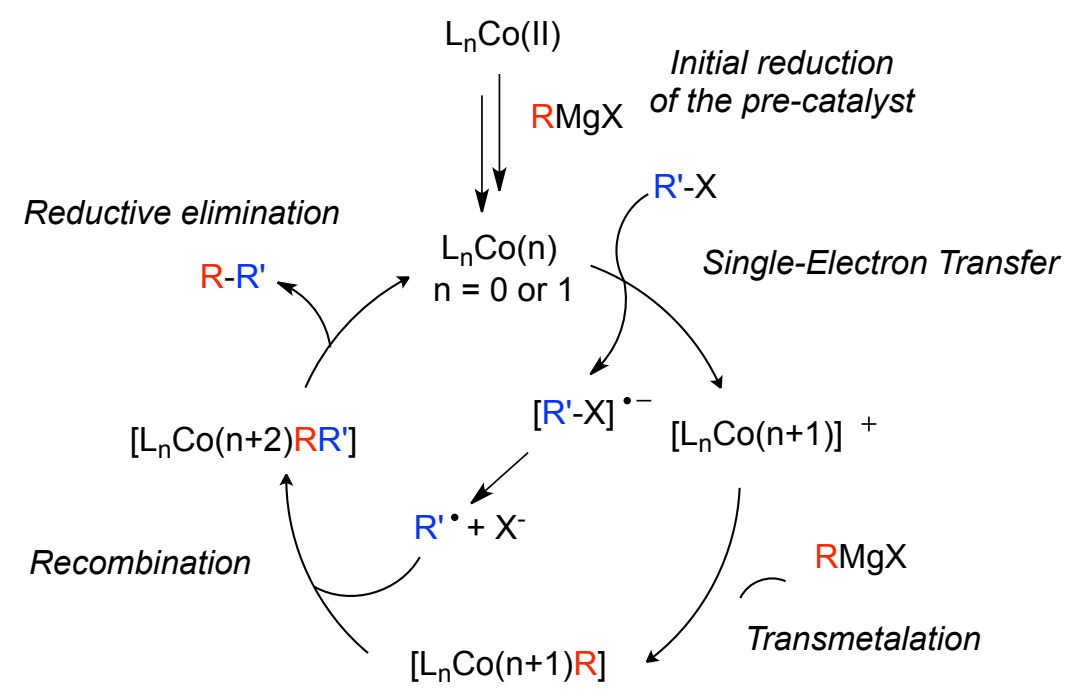

Scheme 32. Hypothetical mechanism of cobalt-catalyzed cross-couplings between alkyl halides and Grignard reagents.

\section{6- Conclusion}

Over the past decade, our group has developed several cobalt catalytic systems allowing the cross-coupling of a range of alkyl halides with aryl-, alkenyl-, cyclopropyl- and cyclobutylGrignard reagents. The reactions are general, robust and the conditions are compatible with a range of functional groups on both substrates and Grignard reagents. The use of abundant, cost- 
effective cobalt complexes associated to available and simple ligands renders these couplings sustainable and generally inexpensive. As such, these reactions appear as an attractive alternative to palladium catalyzed cross-couplings, especially in pharmaceutical industry. Our hope is that these cobalt-catalyzed cross-couplings, will enter in the toolbox of medicinal chemists, as we demonstrate that they are easy-to-handle, robust and general. To fulfill this objective, some efforts still will be needed, notably in term of functional groups compatibility with Grignard reagents.

\section{AUTHOR INFORMATION}

\section{Corresponding Authors}

amandine.guerinot@espci.fr; ORCID : 0000-0002-7002-8215

janine.cossy@espci.fr; ORCID: 0000-0001-8746-9239

\section{Present Addresses}

Molecular, Macromolecular Chemistry and Materials, ESPCI Paris, CNRS, PSL University, 10 rue Vauquelin 75005 Paris.

\section{Authors Biographies}

Amandine Guérinot was born in 1983 in Troyes, France. She graduated as chemical engineer from ESPCI Paris in 2007 and received her Ph. D. in 2010 from the University Pierre et Marie Curie under the supervision of Dr. Sébastien Reymond and Prof. Janine Cossy. She joined the group of Prof. Sylvain Canesi at UQAM, Montreal as a postdoctoral associate and then moved to ICMMO, Orsay, France for a one-year postdoctoral stay with Prof. Vincent Gandon. After a six months postdoctoral fellowship with Dr. Laurent Micouin (Paris Descartes University), she was 
appointed Associate Professor in 2013 at ESPCI Paris in the group of Prof. Janine Cossy. Her research interests include organometallic cross-couplings, sustainable catalysis, synthesis of biologically active compounds and dynamic covalent chemistry.

Janine Cossy early career was spent in Reims, where she did her undergraduate and graduate studies at the University of Champagne-Ardenne, working on photochemistry under the supervision of Prof. Jean-Pierre Pète. After a postdoctoral stay with Prof. Barry M. Trost, for two years at the University of Wisconsin (USA), she returned to Reims where she became, in 1990, Director of Research at the CNRS. In the same year, she moved to Paris where she was appointed Professor of Organic Chemistry at the ESPCI Paris. Janine Cossy's research interests focus on the synthesis of natural products and biologically active molecules and on the development of synthetic methods including organometallic methods. Among the awards, she received the CNRS Bronze Medal (1987), the CNRS Silver Medal (1996), UK Royal Society Rosalyn Franklin International Lecturership awarded to internationally recognized women scientists (UK) (2005), Le Bel Award from the French Chemical Society (France) (2009). In 2013, she was nominated Chevalier de la Légion d'Honneur and in 2015, she obtained the E. C. Taylor Senior Award (USA). She was elected at the French Academy of Sciences in 2017, in 2018 she was promoted Officier de l'Ordre National du Mérite and in 2019, she received the IUPAC 2019 Distinguished Women in Chemistry or Chemical Engineering. She is the co-funder of two companies and was Organic Letters Associate Editor from 2005 to 2018.

\section{Author Contributions}

The manuscript was written through contributions of all authors. All authors have given approval to the final version of the manuscript. 


\section{Funding Sources}

ESPCI Paris, CNRS, Ministère de la Recherche et de l'Enseignement, Sanofi, Janssen Pharmaceutica, Novalix and SFB.

\section{ACKNOWLEDGMENT}

We are deeply indebted to all present and former co-workers, for their experimental and intellectual contributions comprise the work described in this account, particularly Lionel Nicolas, Baptiste Barré, Laurine Gonnard, Etienne Barde, Vanessa Koch, Mélanie Lorion, Claire Andersen, Sébastien Reymond and Stefan Bräse.

We thank Janssen Pharmaceutica, Novalix and Sanofi for financial supports and fruitful collaborations. The French Ministère de l'Enseignement Supérieur et de la Recherche is also acknowledged for grants to PhD students as well as the German SFB/TR88 3MET for a grant.

\section{REFERENCES}

${ }^{1}$ (a) de Meijere, A.; Bräse, S.; Oestreich, M. Metal-Catalyzed Cross-Coupling Reactions and More, 1, 2 and 3. Ed. Wiley 2013. (b) Magano, J.; Dunetz, J. R. Large-scale application of transition metal-catalyzed couplings for the synthesis of pharmaceuticals. Chem. Rev. 2011, 111, 2177. (c) Shinokubo, H.; Oshima, K. Transition metal-catalyzed carbon-carbon bond formation with Grignard reagents - novel reactions with a classic reagent. Eur. J. Org. Chem. 2004, 2081.

${ }^{2}$ (a) Torborg, C.; Beller, M. Recent applications of palladium-catalyzed coupling reactions in the pharmaceutical, agrochemical, and fine chemical industries. Adv. Synth. Catal. 2009, 351, 3027. (b) Johansson Seechurn, C. C. C.; Kitching, M. O.; Colacot, T. J.; Snieckus, V. Palladiumcatalyzed cross-coupling: a historical contextual perspective to the 2010 Nobel prize. Angew. 
Chem. Int. Ed. 2012, 51, 5062. (c) Palladium-catalyzed coupling reactions: practical aspects and future developments. Molnár, A. Ed. Wiley-VCH 2013.

${ }^{3}$ (a) Bihani, M.; Ansari, T. N.; Smith, J. D.; Handa, S. The magical but endangered metal: searching for sustainable palladium catalysis. Curr. Op. Green and sustainable Chem. 2018, 11, 45. (b) Yang, Q.; Babij, N. R.; Good, S. Potential safety hazards associated with Pd-catalyzed cross-coupling reactions. Org. Process. Res. Dev. 2019, 23, 2608.

${ }^{4}$ (a) Holzwarth, M. S.; Plietker, B. Biorelevant metals in sustainable metal catalysis - A survey. Chem. Cat. Chem. 2013, 5, 1650. (b) Hayler, J. D.; Leahy, D. K.; Simmons, E. M. A pharmaceutical industry perspective on sustainable catalysis. Organometallics 2019, 38, 36.

${ }^{5}$ Selected reviews: (a) Sherry, B.D.; Fürstner, A. The promise and challenge of iron-catalyzed cross-coupling. Acc. Chem. Res. 2008, 41, 1500. (b) Enthaler, S.; Junge, K.; Beller, M. Sustainable metal catalysis with iron: from rust to a rising star ? Angew. Chem. Int. Ed. 2008, 47, 3317. (c) Czaplik, W. M.; Mayer, M.; Cvengroš, J.; Jacobi von Wangelin, A. Coming of age: sustainable iron-catalyzed cross-coupling reactions. Chem. Sus. Chem. 2009, 2, 396. (d) Nakamura, E.; Yoshikai, N. Low-valent iron-catalyzed C-C bond formation-addition, substitution, and C-H bond activation. J. Org. Chem. 2010, 75, 6061. (e) Bauer, I.; Knölker, H.-J. Iron catalysis in organic synthesis. Chem. Rev. 2015, 115, 3170. (f) Mako, T. L.; Byers, J. A. Recent advances in iron-catalyzed cross-coupling reactions and their mechanistic underpinning. Inorg. Chem. Front. 2016, 3, 766. (g) Guérinot, A.; Cossy, J. Iron-catalyzed C-C cross-couplings using organometallics. Top. Curr. Chem. 2016, 49, 374. (h) Fürstner, A. Iron catalysis in organic synthesis: a critical assessment of what it takes to make this base metal a multitasking champion. 
ACS Cent. Sci. 2016, 2, 778. (i) Piontek, A.; Bisz, E.; Szostak, M. Iron-catalyzed cross-couplings in the synthesis of pharmaceuticals: in pursuit of sustainability. Angew. Chem. Int. Ed. 2018, 57, 11116.

${ }^{6}$ (a) Evano, G.; Blanchard, N.; Tourni, M. Copper-mediated coupling reactions and their applications in natural products and designed biomolecules synthesis. Chem. Rev. 2008, 108, 3054. (b) Thapa, S.; Shrestha, B.; Gurung, S. K.; Giri, R. Copper-catalyzed cross-coupling: an untapped potential. Org. Biomol. Chem. 2015, 13, 4816.

${ }^{7}$ Selected reviews: (a) Gosmini, C.; Bégouin, J.-M.; Moncomble, A. Cobalt-catalyzed crosscoupling reactions. Chem. Commun. 2008, 3221. (b) Cahiez, G.; Moyeux, A. Cobalt-catalyzed cross-coupling reactions. Chem. Rev. 2010, 110, 1435.

${ }^{8}$ (a) Hu, X. Nickel-catalyzed cross coupling of non-activated alkyl halides: a mechanistic perspective. Chem. Sci. 2011, 2, 1867. (b) Han, F.-S. Transition-metal-catalyzed Suzuki-Miyaura cross-coupling reactions: a remarkable advance from palladium to nickel catalysts. Chem. Soc. Rev. 2013, 42, 5270. (c) Tasker, S. Z.; Standley, E. A.; Jamison, T. F. Recent advances in homogeneous nickel catalysis. Nature 2014, 509, 299.

${ }^{9}$ The use of $\mathrm{Ni}$, Co or $\mathrm{Cu}$ catalysts does not resolve toxicity issues encountered with palladium.

${ }^{10}$ a) Rudolph, A.; Lautens, M. Secondary alkyl halides in transition-metal-catalyzed crosscoupling reactions. Angew. Chem. Int. Ed. 2009, 48, 2656. b) Kambe, N.; Iwasaki, T.; Terao, J. Pd-catalyzed cross-coupling reactions of alkyl halides. Chem. Soc. Rev. 2011, 40, 4937. 
${ }^{11}$ Wakabayashi, K.; Yorimitsu, H.; Oshima, K. Cobalt-catalyzed tandem radical cyclization and cross-coupling reaction: its application to benzyl-substituted heterocycles. J. Am. Chem. Soc. 2001, 123, 5374 .

${ }^{12}$ Ohmiya, H.; Wakabayashi, K.; Yorimitsu, H.; Oshima, K. Cobalt-catalyzed cross-coupling reactions of alkyl halides with aryl Grignard reagents and their application to sequential radical cyclization/cross-coupling reactions. Tetrahedron 2006, 62, 2207.

13 (a) Ohmiya, H.; Yorimitsu, H.; Oshima, K. Cobalt(diamine)-catalyzed cross-coupling reaction of alkyl halides with arylmagnesium reagents: stereoselective constructions of arylated asymmetric carbons and application to total synthesis of AH13205. J. Am. Chem. Soc. 2006, 127, 1886. (b) Someya, H.; Kondoh, A.; Sato, A.; Ohmiya, H.; Yorimitsu, H.; Oshima, K. A new approach to 4-aryl-1,3-butanediols by cobalt-catalyzed sequential radical cyclization-arylation reaction of silicon-tethered 6-iodo-1-hexene derivatives. Synlett 2006, 18, 3061.

${ }^{14}$ Cahiez, G.; Chaboche, C.; Duplais, C.; Moyeux, A. A new efficient catalytic system for the chemoselective cobalt-catalyzed cross-coupling of aryl Grignard reagents with primary and secondary alkyl bromides. Org. Lett. 2009, 11, 277.

15 (a) Hammann, J. M.; Steib, A. K.; Knochel, P. Cobalt-mediated diastereoselective crosscoupling reactions between cyclic halohydrins and arylmagnesium reagents. Org. Lett. 2014, 16, 6500. (b) Hammann, J. M.; Haas, D.; Tüllmann, C.-P.; Karaghiosoff, K.; Knochel, P. Diastereoselective cobalt-mediated cross-couplings of cycloalkyl iodides with alkynyl or (hetero)aryl Grignard reagents. Org. Lett. 2016, 18, 4778. 
${ }^{16}$ In order to gain in chemoselectivity, Negishi-type cross-couplings between alkyl halides and aromatic organozinc reagents were developed, see: a) Hammann, J. M.; Haas, D.; Knochel, P. Cobalt-catalyzed Negishi cross-coupling reactions of (hetero)arylzinc reagents with primary and secondary alkyl bromides and iodides. Angew. Chem. Int. Ed. 2015, 54, 4478. b) Liu, F.; Zhong, J.; Zhou, Y.; Gao, Z.; Walsh, P. J.; Wang, X.; Ma, S.; Hou, S.; Liu, S.; Wang, M.; Wang, M.; Bian, Q. Cobalt-catalyzed enantioselective Negishi cross-coupling of racemic $\alpha$-bromo esters with arylzincs. Chem. Eur. J. 2018, 24, 2059. c) Hofmayer, M. S.; Sunagatullina, A.; Brösamlen, D.; Mauker, P.; Knochel, P. Stereoselective cobalt-catalyzed cross-coupling reactions of arylzinc chlorides with $\alpha$-bromolactones and related derivatives. Org. Lett. 2020, 22, 1286.

${ }^{17}$ Ohmiya, H.; Yorimitsu, H.; Oshima, K. Cobalt-mediated cross-coupling reactions of primary and secondary alkyl halides with 1-(trimethylsilyl)ethenyl- and 2trimethylsilylethynylmagnesium reagents. Org. Lett. 2006, 8, 3093.

${ }^{18}$ (a) Tsuji, T.; Yorimitsu, H.; Oshima, K. Cobalt-catalyzed coupling reaction of alkyl halides with allylic Grignard reagents. Angew. Chem. Int. Ed. 2002, 41, 4137. (b) Ohmiya, H.; Tsuji, T.; Yorimitsu, H.; Oshima, K. Cobalt-catalyzed cross-coupling reactions of alkyl halides with allylic and benzylic Grignard reagents and their application to tandem radical cyclization/cross-coupling reactions. Chem. Eur. J. 2004, 10, 5640.

${ }^{19}$ Someya, H.; Ohmiya, H.; Yorimitsu, H.; Oshima, K. N-Heterocyclic carbene ligands in cobalt-catalyzed sequential cyclization/cross-coupling reactions of 6-halo-1-hexene derivatives with Grignard reagents. Org. Lett. 2007, 9, 1565. 
${ }^{20}$ Cahiez, G.; Chaboche, C.; Duplais, C.; Giulliani, A.; Moyeux, A. Cobalt-catalyzed crosscoupling reactions between functionalized primary and secondary alkyl halides and aliphatic Grignard reagents. Adv. Synth. Catal. 2008, 350, 1484.

${ }^{21}$ Iwasaki, T.; Takagawa, H.; Singh, S. P.; Kuniyasu, H.; Kambe, N. Co-catalyzed crosscoupling of alkyl halides with tertiary alkyl Grignard reagents using 1,3-butadiene additive. $J$. Am. Chem. Soc. 2013, 135, 9604.

${ }^{22}$ Iwasaki, T.; Yamashita, K.; Kuniyasu, H.; Kambe, N. Co-catalyzed cross-coupling reaction of alkyl fluorides with alkyl Grignard reagents. Org. Lett. 2017, 19, 3691.

${ }^{23}$ Very recently, Knochel et al. disclosed a cobalt-catalyzed cross-coupling between alkyl halides and dialkylzinc reagents: Lutter, F. H.; Grokenberger, L.; Benz, M.; Knochel, P. Cobaltcatalyzed $\mathrm{Csp}^{3}-\mathrm{Csp}^{3}$ cross-coupling of functionalized alkylzinc reagents with alkyl iodides. Org. Lett. 2020, 22, 3028.

${ }^{24}$ Nicolas, L.; Angibaud, P.; Stansfield, I.; Bonnet, P.; Meerpoel, L.; Reymond, S.; Cossy, J. Diastereoselective metal-catalyzed synthesis of C-aryl and C-vinyl glycosides. Angew. Chem. Int. Ed. 2012, 51, 11101.

${ }^{25}$ Barré, B.; Gonnard, L.; Campagne, R.; Reymond, S.; Marin, J.; Ciapetti, P.; Brellier, M.; Guérinot, A.; Cossy, J. Iron- and cobalt-catalyzed arylation of azetidines, pyrrolidines and piperidines with Grignard reagents. Org. Lett. 2014, 16, 6160.

26 Gonnard, L.; Guérinot, A.; Cossy, J. Cobalt-catalyzed cross-coupling of 3- and 4iodopiperidines with Grignard reagents. Chem. Eur. J. 2015, 21, 12797. 
${ }^{27}$ Barde, E.; Guérinot, A.; Cossy, J. Cobalt-catalyzed cross-coupling of $\alpha$-bromo amides with Grignard reagents. Org. Lett. 2017, 19, 6068.

${ }^{28}$ Koch, V.; Lorion, M. M.; Barde, E.; Braäse, S.; Cossy, J. Cobalt-catalyzed $\alpha$-arylation of substituted $\alpha$-halogeno $\beta$-lactams. Org. Lett. 2019, $21,6241$.

${ }^{29}$ Andersen, C.; Ferey, V.; Daumas, M.; Bernardelli, P.; Guérinot, A.; Cossy, J. Introduction of cyclopropyl and cyclobutyl ring on alkyl iodides through cobalt-catalyzed cross-coupling. Org. Lett. 2019, 21, 2285.

${ }^{30}$ a) Nicotra, F. Synthesis of C-glycosides of biological interest. Top. Curr. Chem. 1997, 187, 55. b) Compain, P.; Martin, P. R. Carbohydrate mimetics-based glycosyltransferase inhibitors. Bioorg. Med. Chem. 2001, 9, 3077. c) Wu, Q.; Simons, C. Synthetic Methodologies for C-nucleosides. Synthesis 2004, 1533. d) Stanbasky, J.; Hocek, M.; Kosovsky, P. CNucleosides: synthetic strategies and biological applications. Chem. Rev. 2009, 109, 6729.

${ }^{31}$ a) Gong, H.; Sinisi, R.; Gagné, M. R. A room temperature Negishi cross-coupling approach to C-alkyl glycosides. J. Am. Chem. Soc. 2007, 129, 1908. b) Gong, H.; Gagné, M. R. Diastereoselective Ni-catalyzed Negishi cross-coupling approach to saturated, fully oxygenated C-alkyl and C-aryl glycosides. J. Am. Chem. Soc. 2008, 130, 12177.

${ }^{32}$ Lemaire, S.; Houpis, I. N.; Xiao, T.; Li, J.; Digard, E.; Gozlan, C.; Liu, R.; Gavryushin, A.; Diène, C.; Wang, Y.; Farina, V.; Knochel, P. Stereoselective C-glycosylation reactions with arylzinc reagents. Org. Lett. 2012, 14, 1480. 
${ }^{33}$ For a more recent iron-catalyzed arylation of glycosides, see: Adak, L.; Kawamura, S.; Toma, G.; Takenaka, T.; Isozaki, K.; Takaya, H.; Orita, A.; Li, H. C.; Shing, T. K. M.; Nakamura, M. Synthesis of aryl C-glycosides via iron-catalyzed cross coupling of halosugars: stereoselective anomeric arylation of glycosyl radicals. J. Am. Chem. Soc. 2017, 139, 10693.

${ }^{34}$ Guérinot, A.; Reymond, S.; Cossy, J. Iron-catalyzed cross-coupling of alkyl halides with alkenyl Grignard reagents. Angew. Chem. Int. Ed.2007, 46, 6521.

${ }^{35}$ For some examples of radical intermediate formation during Co-catalyzed cross-coupling, see ref. 11, 12, 18b, 19 and: a) Affo, W.; Ohmiya, H.; Fujioka, T.; Ikeda, Y.; Nakamura, T.; Yorimitsu, H.; Oshima, K.; Imamura, Y.; Mizuta, T.; Miyoshi, K. Cobalt-catalyzed trimethylsilylmagnesium-promoted radical alkenylation of alkyl halides: a complement to the Heck reaction. J. Am. Chem. Soc. 2006, 128, 8068. b) Someya, H.; Ohmiya, H.; Oshima, K. Cobalt-catalyzed sequential cyclization/cross-coupling reactions of 6-halo-1-hexene derivatives with Grignard reagents and their application to the synthesis of 1,3 diols. Tetrahedron 2007, 63, 8609.

${ }^{36}$ Giese, B.; Dupuis, J. Anomeric effect of radicals. Tetrahedron Lett. 1984, 25, 1349.

${ }^{37}$ A cis-ring junction was exclusively observed, the indicated diastereomeric ratio concerns the relative stereochemistry of the benzyl substituent and the hydrogens at the ring junction.

${ }^{38}$ Taylor, R. D.; MacCoss, M.; Lawson, A. D. G. Rings in drugs J. Med. Chem. 2014, 57, 5845. 
${ }^{39}$ a) Brandi, A.; Cicchi, S.; Cordero, F. M. Novel syntheses of azetidines and azetidinones. Chem. Rev. 2008, 108, 3988. b) Singh, G. S.; D’hooghe, M.; De Kimpe, N. Azetidines, Azetines and Azetes: Monocyclic; In Comprehensive Heterocyclic Chemistry III; Stevens, C. V., Ed.; Elsevier, Oxford, 2008, Vol 2, Chapter 2.01, p 1 c) Couty, F. ; Evano, G. Azetidines: new tools for the synthesis of nitrogen heterocycles. Synlett 2009, 19, 3053.

${ }^{40}$ A catalytic system composed of $\mathrm{FeCl}_{2}(10 \mathrm{~mol} \%)$ and TMCD (10 mol \%) was also efficient to catalyze this transformation, see ref. 25 .

${ }^{41}$ a) Heel, R. C.; Brogden, R. N.; Speight, T. M.; Avery, G. S. Atenolol: a review of its pharmacological properties and therapeutic efficacy in angina pectoris and hypertension. Drugs 1979, 17, 425. b) Carlberg, B.; Samuelsson, O.; Lindholm, L. H. Atenolol in hypertension: is it a wise choice ? Lancet, 2004, 364, 1684. b) Agon, P.; Goethals, P.; Haver, D. V.; Kaufman, J. Pharm. Pharmacol. 2011, 43, 597.

42 a) Owen, R. T.; Castañer, R.; Bolós, J.; Estivill, C. Almorexant dual orexin OX1/OX2 antagonist treatment of sleep disorders Drugs of the Future 2009, 34, 5.

${ }^{43}$ For other $\alpha$-arylation of carbonyl, see also : (a) Jin, M.; Adak, L.; Nakamura, M. Ironcatalyzed enantioselective cross-coupling reactions of $\alpha$-chloroesters with aryl Grignard reagents. J. Am. Chem. Soc. 2015, 137, 7128. (b) Fu, G. C. Transition-metal catalysis of nucleophilic substitution reactions: a radical alternative to $\mathrm{S}_{\mathrm{N}} 1$ and $\mathrm{S}_{\mathrm{N}} 2$ processes. ACS Cent. Sci. 2017, 3, 692 . 
${ }^{44}$ Under identical conditions, the cross-coupling between the corresponding $\alpha$-chloro- $\beta$-lactam and $p$-methoxyphenylmagnesium bromide delivered the coupling product with a moderate yield of $49 \%$.

${ }^{45}$ A $N$-allyl protecting group was also tolerated.

${ }^{46}$ Selected recent examples: a) Yu, H.; Zhang, G.; Liu, Z.-J.; Huang, H. Palladium-catalyzed carbonylation of allylamines via $\mathrm{C}-\mathrm{N}$ bond activation leading to $\beta, \gamma$-unsaturated amides. $R S C$ Adv. 2014, 4, 64235. b) Fang, X.; Li, H.; Jackstell, R.; Beller, M. Selective palladium-catalyzed aminocarbonylation of 1,3-dienes: atom-efficient synthesis of $\beta, \gamma$-unsaturated amides. J. Am. Chem. Soc. 2014, 136, 16039. c) Li, H.; Neumann, H.; Beller, M. Palladium-catalyzed aminocarbonylation of allylic alcohols. Chem. Eur. J. 2016, 22, 10050. d) Li, H.; Fang, X.; Jackstell, R.; Neumann, H.; Beller, M. Palladium-catalyzed hydroamidocarbonylation of 1,3dienes. Chem. Commun. 2016, 52, 7142. and references therein.

${ }^{47}$ The formation of $\alpha, \beta$-unsaturated amide intermediates followed by subsequent reaction of this electrophilic compound cannot be totally excluded and may explain the moderate yields obtained for the coupling product.

${ }^{48}$ Selected book and reviews: a) Reissig, H.-U. in The Chemistry of the Cyclopropyl Group, (Ed.: Z. Rappoport), Wiley-VCH, 1987. b) Lebel, H.; Marcoux, J.-F.; Molinaro, C. ; Charrette, A. B. Stereoselective cyclopropanation reactions. Chem. Rev. 2003, 103, 977. c) Pietruszka, J. Synthesis and properties of oligocyclopropyl-containing natural products and model compounds. Chem. Rev. 2003, 103, 1051. d) Ganesh, V.; Chandrasekaran, S. Recent advances in the synthesis and reactivity of vinylcyclopropanes Synthesis 2016, 48, 4347. 
${ }^{49}$ See ref. 38 and a) Gagnon, A.; Duplessis, M.; Fader, L. Arylcyclopropanes: properties, synthesis and use in medicinal chemistry. Org. Prep. Proced. Int. 2010, 42, 1. b) Talele, T. T. The « cyclopropyl fragment» is a versatile player that frequently appears in preclinical/clinical drug molecules J.Med.Chem. 2016, 59, 8712 and references therein.

${ }^{50}$ a) Lovering, F.; Bikker, J.; Humblet, C. Escape from flatland: increasing saturation as an approach to improving clinical sucess. J. Med. Chem. 2009, 52, 6752. b) Lovering, F. Escape from flatland 2: complexity and promiscuity. Med. Chem. Commun. 2013, 4, 515.

${ }^{51}$ See for example: a) Qiao, J. X.; Cheney, D. L.; Alexander, R. S.; Smallwood, A. M.; King, S. R.; He, K.; Rendina, A. R.; Luettgen, J. M.; Knabb, R. M.; Wexler, R. R.; Lam, P. Y. S. Achieving structural diversity using the perpendicular conformation of alpha-substituted phenylcyclopropanes to mimic the bioactive conformation of ortho-substituted biphenyl P4 moieties: discovery of novel, highly potent inhibitors of factor Xa. Bioorg. Med. Chem. Lett. 2008, 18, 4118. b) Abe, H.; Kikuchi, S.; Hayakawa, K.; Iida, T.; Nagahashi, N.; Maeda, K.; Sakamoto, J.; Matsumoto, N.; Miura, T.; Matsumura, K.; Seki, N.; Inaba, T.; Kawasaki, H.; Yamaguchi, T.; Kakefuda, R.; Nanayama, T.; Kurachi, H.; Hori, Y.; Yoshida, T.; Kakegawa, J.; Watanabe, Y.; Gilmartin, A. G.; Richter, M. C.; Moss, K. G.; Laquerre, S. G. Discovery of a highly potent and selective MEK inhibitor: GSK1120212 (JTP-74057 DMSO solvate). ACS Med. Chem. Lett. 2011, $2,320$.

${ }^{52}$ See also: (a) Ren, P.; Stern, L.-A.; Hu, X. Copper-catalyzed cross-coupling of functionalized alkyl halides and tosylates with secondary and tertiary alkyl Grignard reagents. Angew. Chem. 
Int. Ed. 2012, 51, 9110. (b) Jia, Z.; Liu, Q.; Peng, X.-S.; Wong, H. N. C. Iron-catalysed crosscoupling of organolithium compounds with organic halides. Nature Comm. 2016, 7, 10614.

${ }^{53}$ For mechanistic studies or discussions see ref. 21, 35a and (a) Kiefer, G.; Vrubel, H.; Scopelliti, R.; Severin, K. The intricate chemistry of cobalt(II) halides and bis(diphenylphosphanyl)ethane. Eur. J. Inorg. Chem. 2013, 4916. (b) Kreyenschmidt, F.; Koszinowski, K. Low-Valent Ate Complexes formed in cobalt-catalyzed cross-coupling reactions with 1,3-dienes as additives. Chem. Eur. J. 2018, 24, 1168. (c) Kreyenschmidt, F.; Meurer, S. E.; Koszinowski, K. Mechanisms of cobalt/phosphine-catalyzed cross-coupling reactions. Chem Eur. J. 2019, 25, 5912. 